Florida International University FIU Digital Commons

\title{
The impact of dieting status and restraint on post- exercise energy intake in overweight females
}

Cristina Visona Andersen

Florida International University

DOI: $10.25148 /$ etd.FI14032313

Follow this and additional works at: https://digitalcommons.fiu.edu/etd

Part of the Dietetics and Clinical Nutrition Commons

\section{Recommended Citation}

Andersen, Cristina Visona, "The impact of dieting status and restraint on post-exercise energy intake in overweight females" (2001). FIU Electronic Theses and Dissertations. 1418.

https://digitalcommons.fiu.edu/etd/1418 


\section{FLORIDA INTERNATIONAL UNIVERSITY}

Miami, Florida

THE IMPACT OF DIETING STATUS AND RESTRAINT ON

POST-EXERCISE ENERGY INTAKE IN OVERWEIGHT FEMALES

A thesis submitted in partial fulfillment of the

requirements for the degree of

MASTER OF SCIENCE

in

DIETETICS AND NUTRITION

by

Cristina Visona Andersen 
To: Dean Vish Prasad

College of Engineering

This thesis, written by Carolyn J. Anderson, and entitled Development and Evaluation of a Geographic Information System Based Method to Estimate Flooding Susceptibility in an Area of Broward County, Florida, having been approved in respect to style and intellectual content, is referred to you for judgment.

We have read this thesis and recommend that it be approved.

Keqi Zhang

Dean Whitman

Stephen P. Leatherman

Hector R. Fuentes, Major Professor

Date of Defense: March 10, 2003

The thesis of Carolyn J. Anderson is approved.

$\begin{array}{r}\begin{array}{r}\text { Dean Vish Prasad } \\ \text { College of Engineering }\end{array} \\ \hline \begin{array}{r}\text { Dean Douglas Wartzok } \\ \text { University Graduate School }\end{array}\end{array}$

Florida International University, 2004 


\section{DEDICATION}

I want to dedicate this thesis to my beloved ones. Thank you Mom, Dad, Jes, Karen and Carlos for your words of encouragement, your helping hand and most importantly, for your unconditional love. 


\section{ACKNOWLEDGMENTS}

Thank you God for giving me the health and motivation to do this project. I am also very grateful to all the participants in this study. I greatly appreciated your enthusiasm, cooperation and your friendliness. I will always cherish the experiences I shared with all of you.

I also wish to express deep gratitude to the members of my committee and Dr. Johnson for all the help they have provided me. Finally, special thanks to Dr. George for being so committed to my project. Your guidance and your support allowed me to have a very enriching research experience. 


\section{ABSTRACT OF THE THESIS \\ THE IMPACT OF DIETING STATUS AND RESTRAINT ON \\ POST-EXERCISE ENERGY INTAKE IN OVERWEIGHT FEMALES \\ by \\ Cristina Visona Andersen}

Florida International University, 2002

Miami, Florida

Professor Valerie George, Major Professor

This study investigated the impact of an acute bout of physical activity on postexercise energy intake (PE-EI) in overweight females who were dieting with high restraint (D-HR) and non-dieting with either high restraint (ND-HR) or low restraint (ND-LR). PE-EI at lunch and 12-hours after was compared on the exercise (E) and a nonexercise (NE) day.

There was a significant interaction $\left(\mathrm{F}_{(2,33)}=4.12, \mathrm{p}=0.025\right)$ of dieting/restraint status and condition (E vs. NE day) on the 12-hour EI. The D-HR ate $519 \pm 596 \mathrm{kcal}$ more on the E than on the NE day; while the ND-HR ate $177 \pm 392 \mathrm{kcal}$ less on the $\mathrm{E}$ than on the NE day.

The results of this study demonstrate that the impact of exercise on PE-EI is determined by both a physiological and psychological response. Dieting status, dietary restraint, level of disinhibition and cognitive factors may influence PE-EI and weight. 
I. INTRODUCTION AND RESEARCH QUESTIONS ................... 1

References........................ 5

II. LITERATURE REVIEW .......................................... 9

Effects of Exercise on Energy Intake, Appetite and Hunger................. 9

The Impact of Cognitive and Psychological Factors on Weight............. 12

Dietary Restraint and Assessment Tools............................... 20

Models of Dietary Restraint and Energy Intake ....................... 32

Perceived Energy Intake and its Effect on Actual Energy Intake............ 35

Perceived Exercise Exertion and its Effect on Post Exercise

Energy Intake................................................ 41

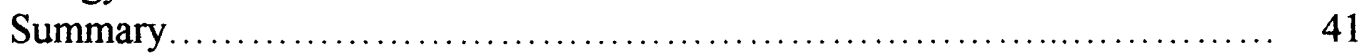

References....................... 58

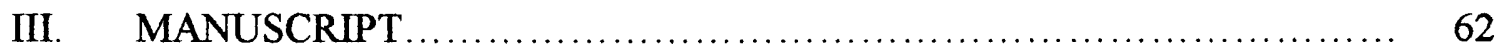

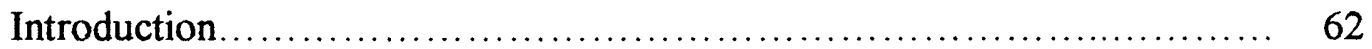

Research Methods and Procedures.................................... 64

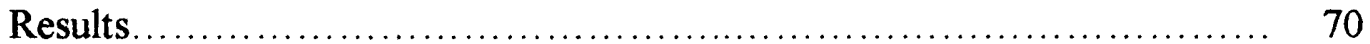

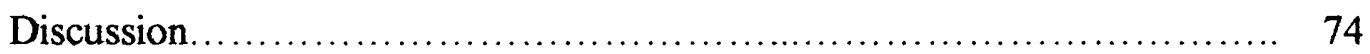

Conclusion and Application......................................... 79

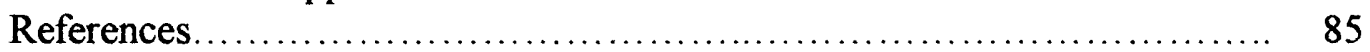

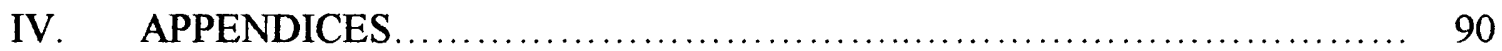




\section{LIST OF TABLES}

TABLE

PAGE

1. Effects of Exercise on Energy Intake, Appetite and Hunger.

2. The Impact of Cognitive and Psychological Factors on Weight.

3. Dietary Restraint in Non Exercise and Exercise Situations.

4. A Model of Dietary Restraint and Post Exercise Energy Intake.

5. Perceived Energy Intake and its Effect on Energy Intake.

6. Descriptive Characteristics of the Participants (Table 1 of Manuscript)

7. Energy Intake (kcal) by Dieting/Restraint Status and Condition, Exercise (E) vs. Non-Exercise (NE) Day (Table 2 of Manuscript)

8. Participant estimation in calories of post-exercise energy expenditure (PE-EE) compared to actual PE-EE (Table 3 of Manuscript).

9. Participant estimation in calories of post-exercise energy intake (PE-EI) compared to actual PE-EI (Table 4 of Manuscript). 


\section{CHAPTER I}

\section{INTRODUCTION AND RESEARCH QUESTIONS}

Over the past twenty years, the prevalence of overweight and obesity, as represented by Body Mass Index, has steadily and markedly increased in the U.S adult (20-74 years of age) population $(1,2)$. In the period from 1988 to 1994 , the crude prevalence of overweight (BMI 25-29) and obesity (BMI $\geq 30$ ) of US adults was $59 \%$ for men, $50 \%$ for women and 54\% overall (2). According to estimates based on NHANES II (19761980) and NHANES III (1988-1994) data, the prevalence for overweight and obesity has increased from $14 \%$ to $22 \%$, respectively (2).

Excess body weight has been associated with the risk of developing a number of chronic illnesses, including heart disease (3-6), diabetes $(7,8)$, osteoarthritis $(9,10)$ and hypertension (11). Obesity and its associated complications (i.e. hyperinsulinaemia, changes in sex hormone levels, elevated visceral adipose tissue level, elevated waist to hip ratio) have also been shown to promote the development of some forms of cancer $(12-17)$.

Being overweight is a major health concern for many Americans, particularly for women (18). A recent survey revealed that in 1996 the prevalence of weight loss and weight maintenance attempts was $28 \%$ and $35 \%$ among men aged 18 or older, and $43 \%$ and $34 \%$ among women of the same age (18). However, despite the magnitude of the efforts directed toward weight loss, overweight and obesity remain a major public health concern in the US (19). 
Exercise has been acclaimed as an important component in weight management, especially when combined with healthy eating habits (i.e. low energy/fat diets) (20-22). Theoretically, exercise has the potential to impact body weight as it may produce a negative energy balance by increasing daily energy expenditure (EE). Review articles indicate that, although still inconclusive, exercise might also elicit an energy deficit through increases in resting metabolic rate (23-25).

The effectiveness of exercise in relation to the energy balance equation and thus, in the prevention and treatment of overweight and obesity, is still not completely understood. In addition, some studies suggest that energy balance is maintained primarily by regulating energy intake (EI) rather than $\mathrm{EE}(26,27)$. Understanding the relationship between exercise and food intake is key to our understanding of how these factors influence body weight.

A number of studies have reported on the relationship between exercise and food intake. The results of most of these studies suggest that there is a weak, short-term coupling between exercise induced EE and post-exercise energy intake (PE-EI) (28-32). That is to say, exercise does not necessarily result in an increase in EI. Findings from a few studies have suggested the opposite (31,33-35). Discrepancies in the results among these studies may be due to the variety of methodological and experimental designs (i.e. differences in exercise intensities and frequency) that have been used. Furthermore, some of these studies have indicated that the effect of exercise on food intake relates to body weight $(28-31,36)$. 
It has also been suggested that psychological (i.e. dietary restraint and disinhibition) and cognitive factors may influence PE-EI (29-32,37-39). It may even be that such factors outweigh physiological or metabolic responses, for example, suppression of appetite and/or hunger induced by exercise. Therefore, it is important to identify the impact of such variables to determine the role they may play in the relationship between exercise and EI (i.e., food compensation) and ultimately, on short or long-term energy balance.

In reference to these issues, this study investigated the impact of dieting status (consciously dieting or not consciously dieting) and restraint, as measured by the ThreeFactor Eating Questionnaire (TFEQ) (40), on PE-EI acutely and twelve hours after a bout of moderate intensity exercise in sedentary overweight women. The restraint factor addresses the cognitive control (i.e. restriction of food intake) of eating behavior in order to control body weight or promote weight loss. We hypothesized that overweight women who were currently dieting and had a high level of dietary restraint would significantly decrease their EI after a bout of moderate intensity physical activity, when compared to overweight women who were not dieting and had a high or low level of dietary restraint.

\section{RESEARCH QUESTIONS}

1. Does current dieting status (defined as actively trying to lose weight or not actively trying to lose weight) influence PE-EI in sedentary overweight women after a moderate bout of exercise? 
2. Does level of dietary restraint have an effect on PE-EI after a moderate bout of exercise in sedentary overweight women, and is there a difference between those who are currently dieting and those who are not?

3. Does level of disinhibition (in relation to dietary restraint) have an effect on PE-EI after a moderate bout of exercise in sedentary overweight women, and is there a different disinhibitory effect of exercise between those who are currently dieting and those who are not?

4. Do cognitive and psychological factors (i.e. food as a reward, perceived PE hunger, etc.) have an effect on PE-EI after a moderate bout of exercise in sedentary overweight women, and does this relate to their current dieting/restraint status? 


\section{REFERENCES}

1. Kuczmarski RJ, Flegal KM, Campbell SM, Johnson CL. Increasing prevalence of overweight among US adults. The National Health and Nutrition Examination Surveys, 1960-1991. JAMA. 1994;272:205-11.

2. Flegal KM, Carroll MD, Kuczmarski RJ, Johnson CL. Overweight and obesity in the United States: prevalence and Trends, 1960-1994. Int J Obes Relat Metab Disord. 1998;22:39-47.

3. Willet WC, Manson JE, Stampfer MJ, et al. Weight, weight change, and coronary heart disease in women. Risk within the "normal" weight range. JAMA. 1995;273:461-5.

4. Manson JE, Colditz GA, Stampfer MJ, et al. A prospective study of obesity and risk of coronary heart disease in women. N Engl J Med. 1990;332:882-9.

5. Kannel WB, Cupples LA, Rammaswami R, Strokes J, Kreger BE, Higgins M. Regional obesity and risk of coronary vascular disease: The Framingham Study. J Clin Epidemiol. 1991;44:183-90.

6. Laver MS, Anderson KM, Kannel WD, Levy D. The impact of obesity on left ventricular mass and geometry. JAMA. 1991;266:231-6.

7. Colditz GA, Willet WC, Rotnitsky AG, Manson JE. Weight gain as a risk factor for clinical diabetes in women. Ann Intern Med. 1995;122:481-6.

8. Lipton RB, Liao Y, Cao G, Copper RS, McGre D. Determinants of incident NIDMM among blacks and whites in a National Sample. Am J Epidemiol. 1993;139:826-39.

9. Anderson JJ, Felson DJ. Factors associated with osteoarthritis of the knee in the first National Health and Nutritional Examination Survey (HANES I): Evidence for an association with overweight, race, physical demands of work. Am J Epidemiol. 1980;128:179-89. 
10. Felson DJ, Anderson JJ, Nalrmark A, Walicer AM, Meenan RF. Obesity and knee osteoarthritis. Ann Intern Med. 1981;109:18-24.

11. De Fronzo RA, Ferrannin IE. A multifaceted syndrome responsible for NIDDM, obesity, hypertension, dyslipidemia, atherosclerotic coronary vascular disease.

Diabetes Care. 1991;14:173-91.

12. Carroll KK. Obesity as a risk factor for certain types of cancer. Lipids. 1998;33:1055-9.

13. Stoll BA. Association between breast and colorectal cancers. Br J Surg. 1998;85:1468-72.

14. Stoll BA. Teenage obesity in relation to breast cancer risk. Int J Obes Relat Metab Disord. 1998;22:1035-40.

15. Schoen RE, Tangen CM, Kuller LH, et al. Increased blood glucose and insulin, body size, and incident colorectal cancer. J Natl Cancer Inst. 1999;91:1147-54.

16. Russo A, Franceschi S, La Vecchia C, et al. Body size and colorectal-cancer risk. Int J Cancer. 1998;78:161-5.

17. Lowenfels AB, Maisonneuve P, Boyle P, Zatonski WA. Epidemiology of gallbladder cancer. Hepatogastroenterology. 1999;46:1529-32.

18. Serdula MK, Mokdad AH, Williamson DF, Galuska DA, Mendlein JM, Heath GW. Prevalence of attempting weight loss and strategies for controlling weight. JAMA. 1999;282:1353-8.

19. Williamson DF, Serdula MK, Anda RF, Levy A, Byers T. Weight loss attempts in adults: goals, duration, and rate of weight loss. Am J Public Health. 1992;82:1251-7.

20. Tremblay A, Doucet E, Imbeault P. Physical activity and weight maintenance. Int J Obes Relat Metab Disord. 1999;23(supppl 3):S50-45. 
21. Westerterp KR. Obesity and physical activity. Int J Obes Relat Metab Disord. 1999;23(suppl 1):S59-64.

22. Tremblay A, Doucet E. Influence of intense physical activity on energy balance and body fatness. Proc Nutr Soc. 1999;58:99-105.

23. Mole PA. Impact of energy intake and exercise on resting metabolic rate. Sports Med. 1990;10:72-87.

24. Poehlman ET. A review: exercise and its influence on resting energy metabolism in man. Med Sci Sports Exerc. 1989;21: 515-25.

25. Van Zant RS. Influence of diet and exercise on energy expenditure: a review. Int $J$ Sport Nutr. 1992;2:1-19.

26. Flatt JP. Dietary fat, carbohydrate balance, and weight maintenance: effects of exercise. Am J Clin Nutr. 1987;45:296-306.

27. Roberts SB, Young VR, Fuss $P$, et al. Energy expenditure and subsequent nutrient intakes in overfed young men. Am J Physiol. 1990;259:R461-9.

28. Bryner RW, Toffle RC, Ullrich IH, Yeater RA. The effects of exercise intensity on body composition, weight loss, and dietary composition in women. $J$ Am Coll Nutr. 1997;16:68-73.

29. Woo R, Garrow JS, Pi-Sunyer FX. Effect of exercise on spontaneous calorie intake in obesity. Am J Clin Nutr. 1982;36:470-7.

30. Woo R, Garrow JS, Pi-Sunyer FX. Voluntary food intake during prolonged exercise in obese women. Am J Clin Nutr. 1982;36:478-84. 
31. Kissilef HR, Pi-Sunyer FX, Segal K. Acute effects of exercise on food intake in obese and non-obese women. Am J Clin Nutr. 1990;52:240-5.

32. Kleim NL, Canty DJ, Barbieri TF, Wu MM. Effect of exercise and dietary restraint on energy intake of reduced obese women. Appetite. 1996;26:55-70.

33. Durrant ML, Royston JP, Wloch RT. Effects of exercise on energy intake and eating patterns in lean and obese humans. Physiol Behav. 1982;29:449-54.

34. Verger P, Lanteaume MT, Louis-Sylvestre J. Free food choices after acute exercise in men. Appetite. 1994;22:159-64.

35. Verger $\mathbf{P}$, Lanteaume MT, Louis-Sylvestre $\mathbf{J}$. Human intake and choices of foods at intervals after exercise. Appetite. 1992;18:93-9.

36. Woo R, Pi-Sunyer FX. Effect of increased physical activity on voluntary intake in lean women. Metabolism. 1982;34:836-41.

37. King NA. What processes are involved in the appetite responses to moderate increase in exercise-induced energy expenditure? Proc Nutr Soc. 1999;58:107-13.

38. Hubert P, King NA, Blundell JE. Uncoupling the effects of energy expenditure and energy intake: appetite response to short-term energy deficit induced by meal omission and physical activity. Appetite. 1998;31:9-19.

39. Thompson DA, Wolfe LA, Eikelboom R. Acute effects of exercise intensity on appetite in young men. Med Sci Sports Exerc. 1988;20:222-7. 


\section{CHAPTER II}

\section{LITERATURE REVIEW}

\section{INTRODUCTION}

This review of literature includes studies that have investigated the effects of exercise on eating behavior, specifically on EI, appetite and hunger. It also presents literature on the role of various cognitive and psychological factors on EI. These studies are summarized in Tables 1-5.

\section{A. Effects of Exercise on Energy Intake, Appetite and Hunger}

\section{Obese vs. Non-obese (Table 1)}

In 1990, Kissileff et al. (1) tried to determine the effects of acute strenuous and moderate exercise on PE-EI in obese (mean BMI 28) and non-obese (mean BMI 22) women. They found that EI (in the form of strawberry yogurt) was significantly reduced in a group of non-obese women immediately after strenuous cycling ( 90 Watts, $40 \mathrm{~min}$ ) compared with non-obese women in the moderate cycling group ( 30 Watts, $40 \mathrm{~min}$ ). However, there was no difference in PE-EI among obese women regardless of the exercise intensity. The obese women did however report greater hunger than the lean individuals after performing a bout of moderate intensity exercise. That is to say, exercise suppressed post-exercise hunger in the non-obese subjects while in the obese subjects exercise did not suppress post-exercise hunger. It is important to mention that the use of a specific (and unusual) post-exercise test meal (strawberry yogurt) does not reflect the food and EI of a free-living situation. 
In reference to this study, although physiological factors were not ruled out, the authors speculated that the obese subjects did not reduce their EI after both the strenuous and moderate intensity exercise bout, because they perceived the strenuous exercise as a difficult task. Consequently, the researchers suggested that the obese women might have felt a need to reward themselves and their reward was to maintain their EI. King (2) has suggested that attitudes and beliefs toward exercise such as "exercise makes you hungry" are very important when considering the relationship between exercise, EI and energy balance.

It is conceivable that the cognitive and psychological state of these obese individuals dominated the exercise-induced physiological effects on EI observed in the non-obese females (suppression of hunger). That is to say, as Kissileff et al. (1) have suggested, obese and non-obese females may have different psychological and cognitive mechanisms that effect the relationship between exercise and EI.

Other studies have presented somewhat contradictory results (3-5). Basically, they have shown that exercise suppresses hunger in obese individuals (3-5). An example of this is a study reported by Durrant et al. (5). They observed twelve obese (mean BMI 38) and four lean (mean BMI 22 \pm 2 ) female and male subjects (19-37 years of age) in a metabolic ward who cycled for three consecutive days (at a minimum of 1000 revolutions/day). The cycling represented an average increase in EE of approximately $100 \mathrm{kcal} /$ day. Ad libitum food intake (from a dispensing machine) was measured over the activity period and compared to a three-day sedentary period. The subjects also completed rating scales for 
hunger (defined as a physiological signal felt inside the body) and appetite (defined as mental signals arising from the desire to eat).

The results of this study (5) showed that during the activity period, both the obese and the non-obese individuals significantly increased the number of eating bouts per day. In addition, exercise suppressed appetite and hunger in all the subjects. There was also significantly greater decrease in appetite and hunger in the obese subjects. However, there were no significant differences in acute EI (both PE-EI and EI at rest) between the obese and lean individuals.

\section{Obese Females (Table 1)}

Two separate studies directed by Woo et al. $(3,4)$ have also looked at the PE eating response of obese people. In their first study, six obese (mean $167 \%$ of ideal body weight) females (22-61 years of age) walked on a treadmill for an average of 111 min/day during two 19-day periods at two different intensities: mild (110\% of sedentary expenditure) and moderate ( $125 \%$ of sedentary expenditure). The second study included only three obese (mean $187 \%$ of ideal body weight) females who underwent a single treadmill walking intensity (moderate or $125 \%$ of sedentary expenditure, $111 \mathrm{~min} /$ day) for 52 days. Both study designs included ad libitum food intake from a mixed diet.

The researchers found that these obese women did not make a significant compensatory increase in EI to match the EE induced by the various exercise intensities. Hence, the subjects remained in a negative energy balance and this resulted in significant fat losses. 
Furthermore, the effect persisted throughout the length of both studies (52 days). These results suggested that either the overweight women had a higher level of dietary restraint or had no increase in appetite. The researchers also suggested that perhaps the latter was due to the fact that the exercise bout was perceived as a tiring and uncomfortable experience.

Overall, the available data from the studies described above (1,3-5) suggests that the beneficial effects (i.e. suppression of hunger) of long-term moderate exercise can be used advantageously to elicit a negative energy balance in overweight females. Although in most of these studies the influence of psychological and cognitive variables were suggested as potential determining factors in PE-EI response, these factors were not assessed.

\section{B. The Impact of Cognitive and Psychological Factors on Weight}

Some studies have found significant relationships among the three factors of human eating behavior (restraint, disinhibition, and susceptibility to hunger), as defined by the TFEQ (6), other behavioral and psychological factors and weight fluctuations in nonexercise situations (7-11). A few studies have investigated this same relationship in exercise situations $(12,13)$. However, no research has focused on the effect of these variables on PE-EI in overweight females who are consciously trying to lose weight and those who are not. 


\section{Non Exercise Situations and Cognitive and Psychological Factors (Table 2)}

Carmody et al. (7) conducted a study to compare obese ( $\geq 120 \%$ of ideal body weight) vs. non-obese ( $<120 \%$ of ideal body weight) adults and weight cyclers vs. weight maintainers on measures of dietary helplessness, nutrition concern, dietary restraint and disinhibition. According to the Nutrition Attitude Survey (8), dietary helplessness was defined as the level of doubt in one's ability to modify unhealthy eating habits and nutrition concern, as the level of concern about healthy eating habits. Cognitive restraint of eating was measured with the TFEQ (6) and defined as the extent of restriction over food intake. In reference to dietary restraint, disinhibition was defined as the extent of loss of control over restricted food intake. These variables were assessed in 385 participants (205 males and 180 females) in the RENO Diet-Heart Study, a 5-year prospective investigation of cardiovascular risk factors, weight fluctuations and behavior patterns.

The results of this study showed that high disinhibition scores and dietary helplessness were significantly related to weight cycling. These scores were significantly greater in participants with a history of weight cycling than in participants with no history of weight cycling. Dietary helplessness was also found to be positively associated with weight status; that is to say, the higher the dietary helplessness, the more likely the person was to be obese. In other words, dietary helplessness increased the risk of subsequent dieting failures and thus, caused the dieters to regain their lost weight. In contrast, dietary restraint and nutrition concern were not found to be significantly associated with weight cycling. Women scored significantly higher on average than men on all the variables 
(dietary helplessness, cognitive restraint and disinhibition) except nutrition concern. According to the authors, this could mean that women perceive dietary issues as less controllable and more problematic than men. In light of all these results, the authors concluded that it is important to consider the relationships between dietary helplessness, disinhibition, obesity and weight cycling when designing interventions to treat obesity.

Foster et al. (9) also assessed the psychological effects of weight loss and regain in obese women (mean BMI 39). Their study included 48 obese women who had completed at least 6 months of a treatment program that combined various levels of energy restriction $(420-1200 \mathrm{kcal} /$ day) with behavior therapy. In their study, the mean weight loss after 6 months of treatment was $21 \pm 8 \mathrm{~kg}$. However, at follow-up (58 months post-treatment) the women were on average $4 \pm 11 \mathrm{~kg}$ above baseline. During the follow-up period, decreases in restraint were significantly correlated with increases in weight. The investigators could not determine whether decreases in restraint led to weight gain or vice versa. It is also important to mention that when participants reached their maximum weight loss (after 6 months of treatment), restraint scores were nearly double $(15 \pm 3)$ than those at baseline $(8 \pm 3)$. However, this dramatic twofold increase was not maintained over time. At followup, the restraint scores averaged $8 \pm 4$. Therefore, one of the principal findings of this study was that although level of restraint correlated with weight loss during treatment, there was no change from baseline to follow-up. On the other hand, reductions in hunger and disinhibition were also observed at follow-up, but these reductions did not significantly relate to the changes in weight. The authors concluded that their results did 
not support the idea that weight loss and regain are associated with increased hunger or a heightened sensitivity to emotional or cognitive disruptions in restraint.

More recently, McGuire et al. (10) tried to determine which behavioral and psychological characteristics occurred in weight gainers compared with weight maintainers. Their study included 714 subjects (initially obese, mean BMI 35), $\geq 18$ years who had already been successful at long-term weight loss (lost at least $30 \mathrm{lbs}$. and maintained this loss for $\geq 1$ year). Weight and weight change history, behavioral (as measured by questionnaires assessing dietary intake and physical activity levels) and psychological information (dietary restraint, disinhibition and hunger) were collected on entry to the study and one year later. The results of this study showed that $35 \%$ of the subjects gained weight $(>5$ lbs.) after the one-year follow up. The weight gain averaged $15 \pm 11 \mathrm{lbs}$. On the other hand, $59 \%$ of the subjects maintained their weight losses $( \pm 5 \mathrm{lbs}$.) and $6 \%$ continued to lose weight ( $>5 \mathrm{lbs}$.). Additionally, $44 \%$ of the gainers reported a series of weight gains and loses over the one year follow-up, whereas, $48 \%$ reported a steady gain throughout the year. Among the maintainers, $41 \%$ reported a series of gains and loses and $50 \%$ reported stable weights during the previous year.

Behavioral characteristics did not differ significantly between gainers and maintainers at the initial assessment. That is to say, at baseline both groups reported eating less than $1500 \mathrm{kcal} /$ day and obtaining less than $25 \%$ of their total EI from fat. Also, they all reported expending over $2500 \mathrm{kcal} /$ week through physical activity. However, at the oneyear follow up, gainers reported greater decreases in EE through physical activity and 
greater increases in percentage calories from fat. In contrast, psychological characteristics measured at baseline were significantly different in those who subsequently gained or maintained their weight. At the initial assessment, gainers reported significantly higher levels of dietary disinhibition. Furthermore, the results showed that higher levels of dietary disinhibition in fact were a risk factor for weight regain. During the one-year follow up, weight gainers reported greater decreases in restraint, and increases in both hunger and dietary disinhibition. Overall, the authors of this study suggested that individuals at risk for weight regain could be best identified by their weight-change history and psychological measures at baseline. They also suggested that weight regain can be due at least in part to failure to maintain behavior changes.

In 1992 Klesges et al. (11) conducted a study to prospectively evaluate the role of dietary intake, physical activity and dietary restraint on changes in body weight over a 1-year period. The cohort included normal weight and overweight men $(n=123)$ and nonpregnant women $(\mathrm{n}=127)$. The results showed that high-restrained (HR), according to Revised Restraint Scale of Herman and Polivy (14), males and females were more likely to be overweight (mean BMI 29 and mean BMI 27, respectively) than their lowrestrained (LR) counterparts (mean BMI 25 and mean BMI 22, respectively). This was true despite lower levels of EI per pound of body weight among the HR subjects, compared to their LR counterparts. However, the HR subjects reported ingesting more energy as fat and less energy as carbohydrates than the LR individuals. According to the authors, the most likely explanation for this finding was that the overweight subjects were more likely to be restrained. Thus, the authors concluded that dietary restraint somehow 
impacts energy balance and consequently, increases the risk of weight gain over time. In addition, high restraint scores predicted weight gain only in women, while they did not do so in men. The authors suggested that such gender difference could be due to the increased prevalence of dieting and binge eating among restrained women which gives them a higher risk of increasing body weight over time.

Tiggemann (12) conducted a study to investigate whether dietary restraint is a predictor of subsequent reported weight loss. The results showed that in a sample of ninety-three (60 women and 33 men, mean age 23 years) normal weight (mean BMI 22) subjects mean weight remained essentially the same $(62 \mathrm{~kg}$. at baseline vs. $63 \mathrm{~kg}$. seven months later) throughout a seven-month period. However, with respect to recent weight fluctuation, restrained eaters, according to Revised Restraint Scale of Herman and Polivy (14), experienced significantly more recent weight loss and weight gain than their unrestrained counterparts. Nonetheless, it should be kept in mind that weight was selfreported, and this might have confounded the results.

In summary, the results of the studies mentioned above $(7,9-12)$ suggest that psychological variables, such as restraint and disinhibition, might have a strong influence on the weight status (i.e. weight fluctuations) of individuals. However, it is still inconclusive if one of these two factors is a stronger predictor of weight loss or weight gain than the other, or if both factors play an equally important role. Another questions that remains unanswered is whether these factors lead to weight cycling or whether unsuccessful weight loss attempts lead to the expression of these psychological factors 
(i.e. being restraint or being disinhibited). Future studies should focus on developing a better understanding of these relationships for more effective weight management interventions.

\section{Exercise Situations and Cognitive and Psychological Factors (Table 2)}

Most weight loss approaches include physical activity. Therefore, the relationship between psychological and cognitive factors and weight (i.e. loss, maintenance, etc.) cannot be fully understood without considering the impact of physical activity and exercise. A study conducted by Folgelholm et al. (13) examined the role of eating control and physical activity on weight maintenance after weight reduction and a very low calorie diet ( $40 \%$ of measured resting EE). Eighty-five obese (mean BMI 34) premenopausal women participated in this 12-month study and underwent two phases: 12 weeks of weight reduction (WR) and 40 weeks of weight maintenance (WM). During the WM period, the subjects were randomly assigned to one of three groups: control (no increase in habitual physical activity), walking group one (EE of $1000 \mathrm{kcal} / \mathrm{week}$ ), or walking group two (EE of $2000 \mathrm{kcal} /$ week). The TFEQ (6) was used to assess dietary restraint before and after the WR program and at the end of the WM intervention.

During the WR program, the mean weight loss for all the groups was $13.5 \mathrm{~kg}$ (range 4.5 $20.8 \mathrm{~kg}$ ) and there was an increase in restraint and binge eating and a decrease in hunger and disinhibition. During the WM program, there was a small mean weight increase of $1.7 \mathrm{~kg}$. and no change in restraint, disinhibition and binge eating. Walking group \#2 had the highest scores for disinhibition and binge eating throughout the study and especially 
during the WM period. However, they did not gain significantly more weight than the two other groups probably because during the WM period, they had significantly higher number of daily steps and higher EE through physical activity. This is significant since it suggests that among these obese women psychological variables (i.e. dietary restraint, disinhibition and binge eating) were influenced by the higher level of exercise. The interplay between these factors would have the potential to influence energy balance.

Wadden et al. (14) set out to determine the changes in body composition, resting energy expenditure (REE), appetite and mood during a 48-week diet and exercise program. One hundred twenty-eight obese females (mean BMI 37) were recruited and randomly assigned into one of four conditions: diet alone; diet plus aerobic training (moderate intensity, $40 \mathrm{~min}$ ); diet plus strength training ( $>14$ repetitions for two sets, $40 \mathrm{~min}$ ); and diet plus aerobic and strength training (40 min, $60 \%$ strength, $40 \%$ aerobic). The prescribed diet consisted of $925-1500 \mathrm{kcal} /$ day. Subjective measures of appetite (hunger, satiety, preoccupation with eating, and intensity of food cravings) were assessed using visual analogue scales at baseline and at weeks 5, 9, 13, 17, 25 and 48. Mood was assessed using the Beck Depression Inventory and the Profile of Mood States.

Participants across the four conditions had a mean weight loss of $15 \pm 8 \mathrm{~kg}$ by week 48 . At this time, the entire group also showed improvements in the measurements of mood (i.e. decline in depression and fatigue and increases in vigor). They also reported significant reductions in hunger (beginning at week 5 and until week 48) and in preoccupation with food (only at week 5) compared with baseline. However, subjective measurement of 
satiety and intensity of food cravings did not differ significantly from baseline. It is very important to mention that throughout the entire study, there were no significant differences among the exercisers and the non-exercisers in any of the measurements mentioned above. That is to say, the researchers failed to find a persistent effect of exercise on these variables. Therefore, the authors concluded that perhaps successful long-term weight loss/control is facilitated by increase in EE through physical activity when coupled with improved mood states. This mood state could eventually encourage individuals to take better control (i.e. adhere to low fat/low calorie diets, exercise) of their weight problem.

The results of the studies mentioned above $(13,14)$ indicate that the effects of psychological and cognitive factors in relation to exercise and long-term weight control are still not clear. It is still uncertain whether exercise in and of itself might prompt any detrimental or beneficial changes in attitudes which might influence EI and ultimately, energy balance.

\section{Dietary Restraint and Assessment Tools}

Dietary restraint has been defined as the cognitive control (i.e. restriction of food intake) of eating behavior in order to control body weight or promote weight loss (6). It can be assessed with the Revised Restraint Scale of Herman and Polivy (15) or with the TFEQ Stunkard and Messick (6). The former consists of 10 items in a Likert scale format and total scores can range from 0 to 35 , where high scores reflect high dietary restraint. Blanchard and Frost (16) developed two factors from this original scale. The first factor, 
"Concern for Dieting", reflects an emotional association with eating and the second factor, "Weight Fluctuation", reflects the extent of previous weight gain and weight loss.

The reliability of this scale has been found to be generally high but its internal consistency can vary depending on the proportion of obese individuals in a studied sample (17). Research has also suggested that this scale has a problem concerning its predictive validity since it fails to predict the eating behavior of obese persons (6). Its construct validity is confounded due to the fact that this scale measures not only dietary restraint but also weight fluctuation, which is a very different construct (6). Dietary restraint and disinhibition are also confounded within the Restraint Scale (18).

In responses to the problems observed with the Restraint Scale of Herman and Polivy (15), Stunkard and Messick (6) developed the Three-Factor Eating Questionnaire (TFEQ). This instrument assesses dietary restraint, disinhibition and hunger.

Disinhibition refers to the loss of control over cognitive dietary restraint due to provoking stimuli (pre-loads of food, ingestion of alcohol and dysphoric emotions) (19). Hunger reflects the tendency to eat in response to subjective feelings of hunger. Laessle et al. (20) have demonstrated the validity of the TFEQ (6) restraint scale with respect to eating behavior.

\section{Dietary Restraint in Non-Exercise Situations (Table 3)}

In 1975 Herman and Mack (21) carried out one of the first studies which considered restraint as an important behavioral mechanism affecting hunger (hunger defined as a physiological signal felt inside the body). Their study consisted of providing high 
restraint (HR) and low restraint (LR) eaters (according to an eating habit questionnaire) with a high-calorie "preload" before having them engage in an "ostensible" taste test. Normal weight $(\leq 10 \%$ overweight $)$ and obese females $(\geq 15 \%$ overweight $)(n=57)$ were randomly assigned to one of three pre-load experimental conditions: 0,1 or 2 milkshakes. Thereafter, they were instructed to eat ad libitum from 3 pints of different ice cream flavors. Weight and degree of restraint in their eating habits were assessed by a 38 -item questionnaire.

Results showed that HR eaters consumed more ice cream after the milkshake pre-load (1 or 2) than after no pre-load at all. Additionally, HR eaters did not discriminate between one or two milkshakes, that is to say, one milkshake was enough to eliminate their restraint. LR subjects behaved in precisely the opposite manner. The authors concluded that the difference among HR and LR eaters could be due to a chronic deprivation state (physical and/or psychological) of the HR eaters. This state could heighten the effect of external cues of hunger and appetite and lead to overeating. Herman and Mack (21) also suggested that the state of restraint, rather than the overweight itself, determined the eating behavior of the obese individuals. Herman and Mack (21) postulated two hypotheses: 1) when the self-control of restrained eaters is somehow violated, eating increases and 2) differences in level of restraint are related to the different eating behaviors observed between obese and normal weight individuals.

Based on these hypotheses, Weber et al. (22) carried out a similar investigation to evaluate the effects of restraint, dietary intake and obesity on both immediate and 
subsequent dietary intake (self-reported). For this study, 112 normal-weight ( $\leq 15 \%$ above ideal weight) and overweight ( $>15 \%$ above their ideal weight) female college students participated in a "pre-load (10-oz. chocolate milkshake) + taste test ( 3 different potato chip flavors)" as described in Herman and Mack's (21) study. The females were classified according to their level of dietary restraint and chronic dieting status utilizing the "Concern for Dieting" (CD) and the "Weight Fluctuation" (WF) factors of the Revised Restraint Scale of Herman and Polivy (15), respectively. The CD factor reflects an emotional association with eating and the WF factor, the extent of previous weight gain and loss.

The results were very different depending on whether the WF factor or the CD factor was used to classify the subjects. When using the WF factor, the results indicated that nondieting obese subjects consumed significantly more calories during the rest of the experimental day than their normal weight non-dieting counterparts. On the other hand, the $\mathrm{CD}$ factor was a more sensitive measurement of the response to the food pre-load. When using this factor it was found that obese and non-obese HR subjects who received a food pre-load reported eating significantly more at the immediate "taste test" (potato chips) and at lunch than their LR counterparts. That is to say, HR eaters failed to appropriately regulate their calorie intake after the high-caloric pre-load. This suggested disinhibition among the HR eaters. Further, among the obese and non-obese subjects not receiving a milkshake pre-load, the HR eaters ate fewer calories than their LR counterparts. In summary, Weber's (22) study supported the hypothesis that HR eaters, regardless of their weight status, eat more whenever their self-control is disrupted. This 
was illustrated as the feeling that the subject had eaten too much once they consumed the pre-load.

A third study using the pre-load + taste paradigm was conducted by Kirschenbaum and Dykman (23) to determine whether self-control skills would influence disinhibited eating normally found in HR eaters. Specifically, they hypothesized that HR eaters who had high self-control skills (HSCS) would eat less ice cream after a pre-load than HR eaters who had low self-control skills (LSCS). Eighty normal weight (BMI 19-26) and overweight (BMI 27-32) females participated in the study and were asked to complete the Revised Restraint Scale of Herman and Polivy (15) and the Self-Control Schedule. Among the high restraint eaters $(n=40) 14 \%$ were overweight, while among the low restraint subjects $(n=40)$ only $2 \%$ were overweight.

The results showed that after consuming the pre-load, the HR eaters with HSCS ate $128 \%$ more ice cream than their LSCS counterparts (and more than both groups of the LR subjects). Thus, high self-control skills accounted for high disinhibitory eating by HR eaters rather than low disinhibitory eating, contrary to what was hypothesized by the researchers. Such results are interesting as they indicate the importance of understanding that high dietary restraint does not always mean success in controlling food intake.

According to Kirschenbaum and Dykman (23), these unexpected results could be explained by the fact that the HR with HSCS had stronger commitments to their dietary goals. Therefore, they felt especially angry and frustrated when the experimenters 
required them to consume the milkshake pre-load. Accordingly, these feelings could have increased their disinhibition towards food.

Altogether the results of the three studies (21-23) mentioned above suggest that chronic deprivation of food (and calories) and the disruption of self-control are some of the possible predictors of dietary restraint and disinhibition. Furthermore, these psychological factors have the potential to influence EI (quantitatively) and ultimately, long term energy balance.

A study conducted by Lawson et al. (24) intended to investigate the influences of dietary restraint and disinhibition upon the following: eating behavior, nutritional intake, energy expenditure (defined as: resting metabolic rate, thermic effect of food and activity) and body composition. A sample of 44 premenopausal, normal weight (mean BMI 21) and overweight (mean BMI 33) women was studied. The TFEQ (6) was used to define the following four groups: High/Low Restraint $\mathrm{x}$ High/Low Disinhibition. The subjects were instructed to record all foods consumed during a two-week period. Simultaneously, they were instructed to subjectively rate the amount of food eaten on a five-point scale ranging from under-eating to bingeing.

The results of this investigation showed that the subjects with high disinhibition (HD) (a score of $\geq 12$ ) did not report higher mean caloric intake over the two weeks of selfmonitoring, than the subjects with low disinhibition (LD) (a score of $\leq 6$ ). However, the subjects with HD reported higher perceived hunger, more bulimic symptoms, more 
frequent subjective episodes of overeating and more frequent lifetime weight cycles (gains or losses of at least $4.5 \mathrm{~kg}$ ), than the subjects with LD. High restraint (HR) (a score of $\geq 13$ ) was only associated with restrictive eating habits (according to the Eating Attitude Test) and a stronger drive for thinness (according to the Eating Disorder Inventory).

HD coupled with low dietary restraint (LR) was also associated with higher adiposity. According to the authors, subjects in the HD/LR group have probably tried to diet frequently (since they are weight cyclers) and thus, they have been very unsuccessful in their efforts to suppress their weight. This behavior has been suggested by Lowe (25) in his three-dimensional model addressing dietary restraint and dieting. Furthermore, lower thermic effect of food and reduced physical activity was found to be associated with the obesity among the HD women. Contrarily, no significant differences were found in resting metabolic rate (controlled for fat free mass) among the four groups mentioned above.

More recently, Lindroos et al. (26) also described how the factors in the TFEQ (6) (dietary restraint, disinhibition and hunger) related to dietary intake and how there were differences in these factors between obese $(n=179$, BMI $>32)$ and non-obese $(n=147$, BMI <28) women. All the subjects also completed a self-administered dietary questionnaire, which assessed food intake during the last three months. 
The results of this investigation were similar to those reported by Lawson et al. (24). Once again, high disinhibition (HD) was associated with obesity. $\mathrm{HD}$ and hunger were strongly associated with higher energy intakes in the obese women compared to the nonobese women. In fact, disinhibition was the strongest TFEQ factor (6) differentiating the obese and the non-obese subjects. Contrarily, within the obese sample, the association between dietary restraint and EI was negative and weaker. No such associations were observed within the non-obese women. In fact, the scores of disinhibition and hunger were generally low in the non-obese group.

The intercorrelations between the TFEQ factors (6) also differed between the obese and the non-obese women. The correlation between restrained eating and disinhibition was significantly negative in the obese group, whereas a weak positive correlation between these two variables was seen in the non-obese women. According to Lindroos et al. (26), this could mean that non-obese disinhibited individuals may be able to control their body weights by restraining food intake. Conversely, obese disinhibited individuals may not be able to control their weights because they do not restrain their food intake and instead tend to overeat.

Based upon the results of these two studies $(24,26)$, it can be concluded that HD was associated with obesity. Therefore, it should be an important factor to consider in the treatment of obese women. On the other hand, HR was associated a stronger desire and ability to control body weight. This suggests that perhaps HR is a better predictor of successful weight maintenance. 


\section{Dietary Restraint in Exercise Situations (Table 3)}

In an effort to further understand the relationship between diet and physical activity in restrained and unrestrained eaters, Tepper et al. (27) looked at food choices, nutrient intakes and activity patterns in 249 young, normal weight females (BMI 19-25) and males (BMI 21-26). Self-reported questionnaires to measure dietary intake and physical activity and the TFEQ (6) were used as assessment instruments.

The results showed that the estimated EI was similar between the HR and LR groups. The authors explained this by stating that since their subjects were young college students, they were all likely to be weight conscious and restrict their EI to some degree, even the LR. Physical activity was also similar between the HR and LR. However, they found that among the most physically active women, HR eaters consumed more carbohydrates and significantly (13\%) less fat than their LR counterparts.

Even though, the findings of this study suggest that in a group of young adults both restraint and exercise was correlated to the food choices and macronutrient intakes of college aged adults, these factors did not correlate to their total EI. It is important to mention that since this study did not include exercise and non-exercise treatment conditions, nor did it measure PE-EI, the above results can not reflect with certainty whether restraint and exercise influence EI or vice versa.

In 1996, King et al. (28) conducted a study to assess the effects of exercise and diet composition on the appetite of thirteen young, normal weight (mean BMI 22) and LR, 
according to the TFEQ (6) females. A year later, Lluch et al. (29) repeated this experiment employing an identical design, but using twelve normal weight (mean BMI 23) and HR females, according to the TFEQ (6), instead of LR females. The studies consisted of four treatment conditions in counterbalanced order: a control (no exercise for $45 \mathrm{~min}$ ) and an intense exercise session (stationary cycling at $70 \% \mathrm{VO}^{2} \max$ for $50 \mathrm{~min}$ ). Both treatments were followed either by a high-fat/low-carbohydrate or low-fat/highcarbohydrate lunch meals. Subjective measures of appetite were monitored via visual analogue scales for motivation to eat (hunger and latency to eat) and sensory attractiveness of foods (palatability).

When Lluch et al. (30) provided a report based on a re-analysis of the data collected from the studies just referenced $(28,29)$, unexpectedly, similar results were found for the HR and LR subjects. In both groups, post-exercise hunger and EI were not suppressed compared to the control (non-exercise) period. EI was significantly greater with the high fat meal than with the low fat meal, however, this was most likely due to the greater energy density of the high-fat meal than to the increasing effect of exercise on hunger and/or appetite. The authors described this response to the exposure of high-fat foods as "passive overconsumption". Finally, they suggested that this phenomenon could overcome the energy deficit induced by physical activity. Interestingly, "passive overconsumption" has also been observed in exercising males who were submitted to similar high-fat diets (31). 
After exercising, the women also reported increased (or enhanced) perception of the palatability, tastiness and pleasantness of the foods they ate at lunch. Yet, this did not induce a drive to eat among both the HR and LR women. That is to say, although exercise raised the perceived pleasantness of foods, it did not induce dietary disinhibition among the women with a higher level of dietary restraint. Therefore, King et al. (28) and Lluch et al. (29) concluded that exercise could be used advantageously to control appetite and PE-EI in HR and LR normal weight women.

The authors suggested that the results would have been different for the HR women if they had been dieting at the time of the study (which they were not). Perhaps, if they had been dieting, the HR women might have chosen to decrease their caloric intake to obtain or to accelerate their weight loss. Conversely, if the exercise bout had provoked disinhibition among these HR dieting females, they would have most likely increased their PE-EI. This behavior has been suggested by Hill et al. in their model addressing dietary restraint, exercise and PE-EI (32).

George and Morganstein also studied the impact of moderate intensity exercise on postexercise energy intake (PE-EI) in reference to body weight and dietary restraint. Normal weight $(n=12, B M I \leq 25)$ and overweight women $(n=12$, BMI $>25)$ with $L R$ and HR participated in a two- day experimental study. On the exercise day, they were asked to walk on a treadmill at $60 \%$ maximum heart rate for one hour. After the exercise, they selected and ate food ad libitum. Their results were similar to those of King et al. (28) and Lluch et al. (29) in that the HR did not eat more on the exercise day compared to the 
non-exercise day. Therefore, the conclusion of these researchers were the same, specifically that participation in moderate intensity exercise did not produce an increase in acute PE-EI in individuals with high restraint regardless of BMI.

Kleim et al. (33) have also investigated the effect of exercise, cognitive restraint, disinhibition and hunger (according to the Eating Inventory) on self-selected food intake. Fifteen healthy women (mean BMI 29) were kept in a metabolic ward for fourteen consecutive days. A choice of prepared food items where available continuously 24 h/day. Additionally, all subjects performed either moderate intensity aerobic exercise (treadmill walking at $\mathrm{VO}^{2}$ max for 29-55 min) or low resistance weight training, five days a week.

The results of this study showed that with both exercise treatments (aerobic and weight training), EI did not increase significantly compared to the non-exercise days. The authors suggested that this apparent uncoupling between EI and EE of exercise could have been due to the greater number of HR eaters $(n=11)$ among their subject sample. Probably, they were cognitively controlling their food intake at the time of the study. However, it was observed that regardless of exercise, seven subjects consistently consumed energy in excess (defined as "overeaters") of their requirement for weight maintenance and the other eight, restricted their EI (defined as "undereaters"). Higher disinhibition and hunger scores contributed significantly to this between subject variance in EI. Additionally, "overeaters" consumed higher proportion of fat and larger evening snacks. 
Based on their findings, Kleim et al. (33) concluded that in this group of women psychological factors (as dietary restraint) had a stronger influence on EI than any physiological signals arising in response to exercise, which could have prompted an increase in PE-EI. They also suggested that individuals who are susceptible to disinhibition and hunger would benefit from weight management strategies to increase their skills at coping with hunger and provoking situations.

In summary, the results of the studies reviewed $(27-29,33)$ suggest that exercise does not precipitate an increase in acute and/or long term EI among women with varying levels of dietary restraint. Therefore, perhaps exercise can be used favorably as a treatment for weight lose or weight maintenance among lean and overweight women. However, it is important to assess and to monitor other psychological variables (i.e. disinhibition) that may influence the eating response to exercise.

\section{Models of Dietary Restraint and Energy Intake}

Hill et al. (32) have suggested that dietary restraint, disinhibition and dieting are many of the factors that can affect PE-EI (Table 4)

\section{Unrestrained Individuals}

According to their proposed model, dietary unrestrained individuals are those who do not diet and do not cognitively control food intake. In addition, unrestrained lean individuals are theoretically the most responsive to physiological cues of hunger and satiety in comparison to both HR lean individuals and LR overweight individuals. Therefore, they 
respond to increased physical activity by increasing their EI; consequently, they remain in energy balance. Contrarily, overweight LR individuals are less sensitive to overall energy demands (than their LR leaner counterparts) and hence, they are less likely to compensate (in terms of EI) for changes in energy expenditure induced by physical activity. This could produce an energy deficit that could lead to weight loss.

It appears that Hill et al. (32) assume that the normal physiological response to exercise is to increase EI in order to match EE as accurately as possible. This supposition differs from the evidence that Rogers (34) has compiled which shows that our physiological system does not control EI in relation to EE.

\section{Restrained Individuals}

In reference to HR individuals, Hill et al. (32) have theorized that both lean and obese individuals that are HR successfully use dieting strategies to cognitively control food intake. Thus, they are less responsive to increased energy demands produced by physical activity than their LR counterparts. They also propose that among HR individuals, current dieting status would be the most important variable affecting EI. That is to say, that a HR individual who is currently dieting might hold constant or, alternately, decrease their EI so that an energy deficit, and subsequent weight loss, is purposely attained or accelerated, respectively. Conversely, a HR subject who is not currently dieting would be unlikely to alter their EI in response to physical activity. 


\section{Disinhibited Individuals}

Finally, Hill et al. (32) propose that overweight disinhibited individuals also regulate their EI in response to physical activity according to their current dieting status. Therefore, during periods of dieting and restraint they would ignore or be unresponsive to hunger signals induced by the physical activity and would behave by holding constant or decreasing EI. Contrarily, during the non-dieting and uncontrolled eating episodes physical activity might actually provide a stimulus for disinhibited eating, resulting in an increased $\mathrm{EI}$ and an overall positive energy balance.

In conclusion, it could be said that perhaps the eating response of both HR and LR individuals is determined by their dieting/restraint status coupled with their vulnerability to become disinhibited.

Lowe (25) has also proposed a three-dimensional model of dietary restraint and dieting. He observed that HR eaters could be described with three factors: history of dieting, current dieting and weight suppression (or successful weight reduction via dieting). According to his model, subjects in the High Restraint (HR)/Low Disinhibition (LD) category probably represent subjects that have dieted frequently in the past, are currently trying to diet and are successful at suppressing weight gain. Contrarily, subjects in the Low Restraint (LR)/High Disinhibition (HD) group have had a history of frequent dieting but are not currently dieting, and have been very unsuccessful in their efforts at weight suppression. The last group, the HR/HD individuals, may represent subjects who have a 
history of frequent dieting, are currently attempting to diet, yet they struggle to control their weight due to episodic overeating.

\section{E. Perceived Energy Intake and its Effect on Actual Energy Intake}

\section{Non Exercise Situations (Table 5)}

Wooley et al. (35) were among the first researchers to conduct a study to determine if subjects can perceive (metabolically) excess or deficit of calories above or below their usual caloric intake, and if this affects hunger and satiety. Seven obese (at least $18 \%$ above their ideal weight) and seven non-obese (within $10 \%$ of ideal body weight) subjects were given a series of identical high-calorie $(1 \mathrm{cal} / \mathrm{cc})$ and low-calorie $(0.6$ $\mathrm{kcal} / \mathrm{cc}$ ) liquid meals for breakfast or lunch. The volume of each subjects' liquid meal was determined so that they received as many calories as they usually ate at the specific meal (breakfast or lunch) that was replaced by the liquid meal. Following the meal, the subjects indicated how hungry they felt and whether they thought the meal was high calorie or low calorie.

The results showed that the individuals had almost no ability to correctly identify the meals as high or low calorie (level of accuracy was only $51 \%$, or 114 out of 222 judgements). Therefore, it was shown that the actual caloric content of the liquid meal had little effect on the subjects' ratings of hunger. However, hunger was highly related to the "judged" caloric content of the test meal, regardless of a correct or incorrect judgement. In conclusion, according to the researchers, hunger (and thus, EI) may be more dependent upon how much satisfaction is believed to be inherent in the meal. 
Ogden and Wardle (36) conducted a very similar experiment with the purpose of studying the effect of cognitive restraint on the sensitivity to internal (physiological) and external (cognitive) cues of hunger and satiety. The study was designed to compare the sensitivity to these cues in HR $(n=10)$ and LR $(n=10)$ eaters (Restrained Eating Scale of the Dutch Eating Behavior Questionnaire). As in the previous study, the subjects were given either a high calorie $(300 \mathrm{kcal})$ or low calorie $(50 \mathrm{kcal})$ drink, but they were either correctly or incorrectly told its calorie content. They also rated (using visual analogue scales) their subjective hunger and satiety responses after the test meal.

All subjects, regardless of their restraint level, reported greater decrease in hunger and increase in fullness after the high calorie drink than after the low calorie drink. That is to say, all subjects (HR and LR) were sensitive to the internal (physiological) cues of hunger (decreased) and satiety (increased) induced by the high calorie drink. In addition, the HR eaters' ratings of hunger were also influenced by the believed caloric content of the drink. In other words, the HR eaters showed evidence of greater sensitivity to the manipulation of external cues (believed caloric content of the drink). They reported being less hungry if they were told the drink was high in calories and hungrier if they were told the drink was low in calories than their LR counterparts. However, the effect of this external cue manipulation was not significant.

Interestingly, the hunger ratings among the HR eaters did not significantly affect their food intake during the test meal. In other words, the HR subjects' EI was almost the same regardless of the believed caloric intake of the drink. EI was also similar among the LR 
eaters during the two testing conditions. That is to say, neither HR nor LR eaters showed any significant response to either the external (believed caloric content) or the internal (actual caloric content) cue manipulation. The authors concluded that the observed consistency in food intake, despite cue manipulations, suggested that habitual factors may be more important determinants of eating, especially if the meal is given at the usual time. Moreover, in comparison to the HR eaters, the LR eaters consumed significantly more at the test meal, irrespective of the condition (high/low calorie drink). This suggested that during this study, the HR eaters were successfully restricting their food intake and that restraint had a significant effect on food intake. In conclusion, it can be said that both HR and LR eaters were responsive to internal (physiological) cues of hunger induced by variations in caloric load. The HR eaters showed an additional sensitivity to external (cognitive) cues of hunger and satiety induced by the believed caloric content of the drink.

Huon et al. (37) conducted a similar experiment with $56 \mathrm{HR}$ and LR, according to the TFEQ (6), normal weight (BMI 23) college females. Specifically, their objective was to study the role of restraint and disinhibition in appetite control. In this study, the subjects were given either a high $\mathrm{CHO}(74 \%)$ or low $\mathrm{CHO}(44 \%)$ breakfast (instead of a high/low calorie drink) with equal caloric content. Again the subjects were correctly or incorrectly told its $\mathrm{CHO}$ content. Measures were taken of their desire for food and their willingness to eat, as well as their total ad libitum EI at a test meal provided 4 hours later. 
The results showed that LR eaters ate significantly more ad libitum in their meal after the $74 \%$ than the $44 \%$ CHO breakfast. This occurred even when they knew they had consumed a higher proportion of $\mathrm{CHO}$ during their morning meal. HR subjects behaved oppositely. They ate more of the test meal after having the $44 \%$ than the $74 \% \mathrm{CHO}$ breakfast, and ate less of the test meal when they knew they had eaten a higher proportion of $\mathrm{CHO}$. That is to say, telling the $\mathrm{HR}$ eaters the $\mathrm{CHO}$ content of their meal (even if the CHO content was high) did not disrupt their restraint, as calorie rich foods (milk shake pre-loads) have been shown to do $(21,22)$. Instead, giving HR eaters this information (CHO content of their meal) increased their restraint. They showed a decrease in their appetite and EI after having the high CHO breakfast.

It is important to mention that perhaps the experiment conducted by Huon et al. (37) did not have the correct control to show that the information provided actually had an effect on EI and appetite. The authors assumed that the subjects understood what a high/low CHO breakfast meant. That is to say, the way this information was translated into each subject's understanding was not controlled.

Knight and Boland (38) conducted three studies to evaluate the influence of perceived calories and food types in the eating patterns of college females $(n=84, n=93, n=73$, respectively). The first study revealed that HR eaters, according to the Revised Restraint Scale of Herman and Polivy (14), evaluated a larger number of foods as forbidden (foods that they believed should be avoided on a weight reduction diet) than the LR eaters. Hence, the authors suggested that HR eaters are more restricted simply because they see 
more foods as high caloric or as forbidden than LR eaters. That is to say, there is an association between restraint and the avoidance of certain foods.

Their second study examined the separate effects of caloric value and food type (permitted/forbidden) on eating behaviors. Interestingly, the results showed that normal weight HR eaters ate more of a test meal (three flavors of ice cream) following a "forbidden food" pre-load (ice cream) than following a "permitted food" pre-load (cottage cheese) of equivalent caloric content. That is to say, the "forbidden food" caused greater disinhibition regardless of the perceived caloric value of both pre-loads (they were not told the actual caloric content of the pre-loads).

In their third experiment, the researchers specifically examined the effect of anticipated (expected) consumption on the restraint eating pattern and the amount of food eaten during a test meal. First, the participants were randomly assigned to one of the following anticipatory conditions (varying food type and calories):

a) Expecting to eat nothing after the test meal (control)

b) Expecting to eat a high calorie/forbidden food ( $400 \mathrm{kcal}$, milkshake) after test meal

c) Expecting to eat a low calorie/forbidden food ( $150 \mathrm{kcal}$, ice cream bar) after test meal

d) Expecting to eat a high calorie/permitted food ( $400 \mathrm{kcal}$, chef's salad) after test meal

e) Expecting to eat a low calorie/permitted food ( $150 \mathrm{kcal}$, vegetable salad) after test meal 
After been assigned to one of the anticipatory conditions, they were instructed to rate the taste of a test meal (three different kinds of crackers). The results showed that despite having been informed of the caloric content of each food item, HR eaters ate more of the test meal (crackers) when they anticipated a forbidden food than when they anticipated a permitted food, when compared to the LR eaters. For example, HR subjects who expected to eat a low calorie forbidden food $(150 \mathrm{kcal}$, ice cream bar) ate almost twice as much of the test meal than when they expected to eat a permitted food with the same caloric content ( $150 \mathrm{kcal}$, vegetable salad) (51 g versus $26 \mathrm{~g}$, respectively). The same observation was made with the high calorie forbidden food ( $400 \mathrm{kcal}$, milkshake) versus the equivalent high calorie permitted food ( $400 \mathrm{kcal}$, chef's salad) (50 g versus $21 \mathrm{~g}$, respectively). Nonetheless, it is important to mention that the use of an unusual test meal (crackers), which does not reflect the food and energy intake of a free-living situation, could have possibly influenced these results.

Overall, the findings of these studies (35-38) suggest that among HR individuals disinhibited eating is triggered more by the belief that the foods that they are consuming are high in calories, high in a specific macronutrient and/or forbidden, than by the actual caloric/macronutrient content of these food items. Therefore, this suggests that beliefs concerning what foods are acceptable or forbidden, satisfactory or dissatisfactory are major factors influencing not only EI but macronutrient intake as well. 


\section{F. Perceived Exercise Exertion and its Effect on Post Exercise Energy Intake}

Several researchers have suggested that the perception of exercise exertion appears to have a strong influence on PE-EI $(1,3,4,39,40)$. It has been further suggested that in such situation, the perceived exercise exertion can have a stronger influence in reducing EI and hunger than the actual exercise exertion involved (40). Some authors also hypothesize that if exercise is perceived as a tiring and uncomfortable experience, EI is reduced (specifically in obese women) $(3,4,39,40)$.

Contrarily, other authors have suggested that when exercise is perceived as a strenuous and difficult task, individuals (especially obese women) feel a need to reward themselves (1). The "reward" being to maintain their normal EI, rather than decreasing EI. Additionally, the restraint theory by Hill et al. (32) hypothesizes that restraint eaters eat in response not only to physiological hunger cues, but also in response to a variety of external (i.e., food availability and palatability) and internal (i.e., physical or emotional) cues.

\section{SUMMARY}

The relationship between exercise, EI and energy balance is still quite inconclusive. Apparently, this is due to a variety of factors that might strongly influence the association between them. Exercise (i.e. modality, intensity, duration, frequency) and personal characteristics (i.e. body weight and composition, dietary restraint and disinhibition, dieting status, dieting and exercising habits, beliefs and perceptions related to EI and EE) appear to have a determining impact on PE-EI, and subsequently, on body weight. 
Internal (i.e. physiology) and external cues (i.e. food availability, environment) might also have an important role on the outcome of exercise on eating response, whether it is a suppressive or an enhancing effect. The results of several "non-exercise" studies have shown that the interaction between personal characteristics, especially psychological and cognitive factors, and internal/external cues has a decisive impact on EI and weight management. However, it is still not well understood how these variables interact with one another once the exercise component is included.

It is important to further investigate this issue to provide health care professionals with information that can help them tailor weight loss strategies in reference to the individual factors that could influence PE-EI. A better understanding of this issue could assist health care professionals and dietitians to ultimately reduce the prevalence of overweight and obesity and aid in the prevention of the associated chronic diseases and other health complications. 
Table 1. Effects of Exercise on Energy Intake, Appetite and Hunger

\begin{tabular}{|c|c|c|c|c|}
\hline $\begin{array}{l}\text { AUTHOR(S) } \\
\text { AND YEAR }\end{array}$ & SUBJECTS & OBJECTIVE & $\begin{array}{l}\text { EXERCISE INTESITIES } \\
\text { AND FOOD INTAKE } \\
\end{array}$ & RESULTS \\
\hline \multicolumn{5}{|c|}{ OBESE VERSUS NON OBESE } \\
\hline $\begin{array}{l}\text { Kissileff et al } \\
\text { (1990) }\end{array}$ & $\begin{array}{c}\mathrm{N}=9 \text { obese } \\
\text { females } \\
\text { (BMI } 27.72 \pm 0.90) \\
\text { and } 9 \text { non obese } \\
\text { females (BMI } \\
22.14 \pm 1.78 \text { ) } \\
\text { age }=18-35\end{array}$ & $\begin{array}{l}\text { To determine the } \\
\text { effects of acute } \\
\text { strenuous and moderate } \\
\text { exercise on food intake } \\
\text { on obese and non obese } \\
\text { women }\end{array}$ & $\begin{array}{c}\text { Stationary cycling } \\
\text { No exercise (control), } \\
\text { Strenuous ( } 90 \mathrm{~W}, 40 \mathrm{~min}), \\
\text { Moderate (30 W } 40 \mathrm{~min}) \\
\text { Standardized breakfast and } \\
\text { test meal (yogurt shake) } 15 \\
\text { min post }\end{array}$ & $\begin{array}{c}\text { EI decreased significantly with } \\
\text { strenuous exercise in the non } \\
\text { obese } \\
\text { EI was not significantly } \\
\text { different in the obese with the } \\
\text { two exercise intensities } \\
\text { Hunger was significantly } \\
\text { higher with moderate exercise } \\
\text { in the obese }\end{array}$ \\
\hline $\begin{array}{l}\text { Durrant et al } \\
\quad(1982)\end{array}$ & $\begin{array}{c}\mathrm{N}=1 \text { lean male, } \\
3 \text { lean females } \\
(\mathrm{BMI} 21.8 \pm \mathbf{2 . 1}) \\
\text { age }=22 \pm 3 \\
\text { and } 1 \text { obese male, } \\
\text { 11 obese } \\
\text { females } \\
\text { (BMI } 37.6 \pm 7.5) \\
\text { age }=27 \pm 10\end{array}$ & $\begin{array}{l}\text { To make detailed, } \\
\text { accurate, short term } \\
\text { measurements of food } \\
\text { intake and eating } \\
\text { patterns during non } \\
\text { exercise and exercise } \\
\text { periods }\end{array}$ & $\begin{array}{c}\text { Stationary cycling } \\
\text { Minimum of } 1000 \\
\text { revolutions/day } \\
\text { Ad libitum food intake from a } \\
\text { dispensing machine } \\
\text { Hunger and appetite rated } \\
\text { seven times a day } \\
\text { Mood rated at the end of the } \\
\text { day }\end{array}$ & $\begin{array}{c}\text { No significant differences in } \\
\text { eating patterns and mood } \\
\text { between obese and non obese } \\
\text { Significantly higher number of } \\
\text { eating bouts per day on } \\
\text { exercise days } \\
\text { Significantly lower daily } \\
\text { appetite and hunger on } \\
\text { exercise days, especially for } \\
\text { the obese } \\
\text { EI was significantly different } \\
\text { with time, lean ate more and } \\
\text { obese ate less } \\
\text { Well being was significantly } \\
\text { greater with time in the lean }\end{array}$ \\
\hline
\end{tabular}


Table 1. Effects of Exercise on Energy Intake, Appetite and Hunger

\begin{tabular}{|c|c|c|c|c|}
\hline $\begin{array}{l}\text { AUTHOR(S) } \\
\text { AND YEAR }\end{array}$ & SUBJECTS & OBJECTIVE & $\begin{array}{l}\text { EXERCISE INTESITIES } \\
\text { AND FOOD INTAKE }\end{array}$ & RESULTS \\
\hline \multicolumn{5}{|c|}{ OBESE FEMALES } \\
\hline $\begin{array}{l}\text { Woo et al } \\
(1982)\end{array}$ & $\begin{array}{l}\mathrm{N}=6 \text { obese } \\
\text { (167\% of their } \\
\text { ideal weight) } \\
\text { age }=22-61 \\
\text { age }=42\end{array}$ & $\begin{array}{l}\text { To determine the effect } \\
\text { of increased physical } \\
\text { activity on EI and } \\
\text { balance on obese } \\
\text { women }\end{array}$ & $\begin{array}{c}\text { Treadmill walking } \\
\text { No exercise (control), } \\
\text { Mild ( } 110 \% \text { of No exercise } \\
\text { expenditure) and } \\
\text { Moderate ( } 125 \% \text { of No } \\
\text { exercise expenditure) } \\
\text { Time varied among } \\
\text { participants } \\
\text { Mixed diet eaten ad libitum }\end{array}$ & $\begin{array}{l}\text { No significant change in EI with } \\
\text { exercise intensities } \\
\text { EI did not increase and did not } \\
\text { exceed EE with mild or } \\
\text { moderate exercise }\end{array}$ \\
\hline $\begin{array}{l}\text { Woo et al } \\
(1982)\end{array}$ & $\begin{array}{c}N=3 \text { obese } \\
\text { (187\% of their } \\
\text { ideal weight }) \\
\text { age }=30\end{array}$ & $\begin{array}{l}\text { To determine the effect } \\
\text { of } 57 \text { days of moderate } \\
\text { physical activity on EI } \\
\text { and energy balance }\end{array}$ & $\begin{array}{l}\text { Treadmill walking: Moderate } \\
(125 \% \text { of No exercise } \\
\text { expenditure, } 111 \mathrm{~min} / \text { day }) \\
\text { Mixed diet eaten ad libitum }\end{array}$ & $\begin{array}{l}\text { No significant change in EI with } \\
\text { moderate exercise intensity } \\
\text { EI did not increase and did not } \\
\text { exceed EE with moderate } \\
\text { exercise } \\
\text { EI was not altered with time, the } \\
\text { effect persists over time }\end{array}$ \\
\hline
\end{tabular}


Table 2. The Impact of Cognitive and Psychological Factors on Weight

\begin{tabular}{|c|c|c|c|c|}
\hline $\begin{array}{l}\text { AUTHOR(S) } \\
\text { AND YEAR }\end{array}$ & SUBJECTS & OBJECTIVE & $\begin{array}{l}\text { VARIABLES MEASURED/ } \\
\text { INTERVENTION }\end{array}$ & RESULTS \\
\hline \multicolumn{5}{|c|}{ IN NON EXERCISE SITUATIONS } \\
\hline $\begin{array}{c}\text { Carmody et al } \\
(1995)\end{array}$ & $\begin{array}{c}\mathrm{N}=385 \text { obese } \\
\text { males and females } \\
(\geq 120 \% \text { of ideal } \\
\text { body weight) and } \\
\text { non-obese } \\
(<120 \% \text { of ideal } \\
\text { body weight) }\end{array}$ & $\begin{array}{l}\text { To compare obese } \\
\text { versus non obese adults } \\
\text { and weight cyclers } \\
\text { versus maintainers on } \\
\text { measures of dietary } \\
\text { helplessness, nutrition } \\
\text { concern, dietary } \\
\text { restraint and } \\
\text { disinhibition }\end{array}$ & $\begin{array}{l}\text { Dietary helplessness and } \\
\text { Nutrition concern } \\
\text { (Nutrition Attitude Survey); } \\
\text { Dietary restraint and } \\
\text { disinhibition } \\
\text { (TFEQ) }\end{array}$ & $\begin{array}{c}\text { Disinhibition and dietary } \\
\text { helplessness significantly related } \\
\text { to weight cycling } \\
\text { Dietary restraint and nutrition } \\
\text { concern not significantly related } \\
\text { to weight cycling } \\
\text { Dietary helplessness positively } \\
\text { related to weight status }\end{array}$ \\
\hline $\begin{array}{c}\text { Foster et al } \\
(1996)\end{array}$ & $\begin{array}{l}\mathrm{N}=480 \mathrm{bese} \\
\text { females } \\
(\mathrm{BMI} 39 \pm 6)\end{array}$ & $\begin{array}{l}\text { To assess the } \\
\text { psychological effects of } \\
\text { weight loss and regain }\end{array}$ & $\begin{array}{c}\text { Mood } \\
\text { (Beck Depression Inventory); } \\
\text { Binge eating } \\
\text { (Binge Eating Scale); } \\
\text { Restraint, disinhibition \& } \\
\text { hunger } \\
\text { (TFEQ) }\end{array}$ & $\begin{array}{l}\text { Decreases in restraint } \\
\text { significantly correlated with } \\
\text { increases in weight } \\
\text { Reductions in hunger and } \\
\text { disinhibition not significantly } \\
\text { related to increases in weight }\end{array}$ \\
\hline
\end{tabular}


Table 2. The Impact of Cognitive and Psychological Factors on Weight

\begin{tabular}{|c|c|c|c|c|}
\hline $\begin{array}{l}\text { AUTHOR(S) } \\
\text { AND YEAR }\end{array}$ & SUBJECTS & OBJECTIVE & $\begin{array}{l}\text { VARIABLES MEASURED/ } \\
\text { INTERVENTION }\end{array}$ & RESULTS \\
\hline \multicolumn{5}{|c|}{ IN NON EXERCISE SITUATIONS CONTINUED } \\
\hline $\begin{array}{l}\text { McGuire et al } \\
\text { (1999) }\end{array}$ & $\begin{array}{c}\mathrm{N}=714 \text { obese males } \\
\text { and females } \\
\text { (BMI 35) }\end{array}$ & $\begin{array}{c}\text { To identify } \\
\text { predictors of } \\
\text { weight gain versus } \\
\text { continued } \\
\text { maintenance } \\
\text { among individuals } \\
\text { already successful } \\
\text { at long-term weight } \\
\text { loss }\end{array}$ & $\begin{array}{c}\text { Dietary intake } \\
\text { Energy expenditure (EE) } \\
\text { (Paffenbarger Activity } \\
\text { Questionnaire) } \\
\text { Restraint, disinhibition \& } \\
\text { hunger } \\
\text { (TFEQ) } \\
\text { Binge eating } \\
\text { (Eating Disorder Examination) }\end{array}$ & $\begin{array}{l}\text { Weight gainers reported } \\
\text { greater decreases in EE and } \\
\text { greater increases in percentage } \\
\text { calories from fat } \\
\text { Weight gainers reported } \\
\text { greater decreases in restraint, } \\
\text { and increases in both hunger and } \\
\text { dietary disinhibition }\end{array}$ \\
\hline $\begin{array}{l}\text { Klesges et al } \\
\text { (1992) }\end{array}$ & $\begin{array}{c}\mathrm{N}=250 \text { normal weight } \\
\text { (BMI 24.73-22.50) and } \\
\text { overweight (BMI } \\
29.16-26.96) \text { males and } \\
\text { females }\end{array}$ & $\begin{array}{l}\text { To evaluate the } \\
\text { role of dietary } \\
\text { intake, physical } \\
\text { activity and dietary } \\
\text { restraint on } \\
\text { changes in body } \\
\text { weight }\end{array}$ & $\begin{array}{c}\text { Dietary intake } \\
\text { Physical activity (PA) } \\
\text { (Baecke PA Questionnaire) } \\
\text { Restraint } \\
\text { (Revised Restraint Scale of } \\
\text { Herman and Polivy) }\end{array}$ & $\begin{array}{l}\text { High-restraint subjects were } \\
\text { more likely to be overweight } \\
\text { High restraint scores predicted } \\
\text { weight gain only women }\end{array}$ \\
\hline
\end{tabular}


Table 2. The Impact of Cognitive and Psychological Factors on Weight

\begin{tabular}{|c|c|c|c|c|}
\hline $\begin{array}{c}\text { AUTHOR(S) } \\
\text { AND YEAR }\end{array}$ & SUBJECTS & OBJECTIVE & $\begin{array}{c}\text { VARIABLES MEASURED/ } \\
\text { INTERVENTION }\end{array}$ & RESULTS \\
\hline \multicolumn{1}{|c|}{ Tiggemann (1994) } & $\begin{array}{c}\text { N=93 normal } \\
\text { weight males } \\
\text { and females } \\
\text { (BMI 21.8) }\end{array}$ & $\begin{array}{c}\text { To investigate dietary } \\
\text { restraint as a predictor } \\
\text { of subsequent reported } \\
\text { weight loss }\end{array}$ & $\begin{array}{c}\text { Restraint } \\
\text { (Bevised Restraint Scale of } \\
\text { Herman and Polivy) }\end{array}$ & $\begin{array}{c}\text { Restrained eaters experienced } \\
\text { significantly more recent weight } \\
\text { loss and weight gain than their } \\
\text { unrestrained counterparts }\end{array}$ \\
\hline Folgelholm et al \\
(1999)
\end{tabular}


Table 2. The Impact of Cognitive and Psychological Factors on Weight

\begin{tabular}{|c|c|c|c|c|}
\hline $\begin{array}{l}\text { AUTHOR(S) } \\
\text { AND YEAR }\end{array}$ & SUBJECTS & OBJECTIVE & $\begin{array}{l}\text { VARIABLES MEASURED/ } \\
\text { INTERVENTION }\end{array}$ & RESULTS \\
\hline \multicolumn{5}{|c|}{ IN EXERCISE SITUATIONS CONTINUED } \\
\hline $\begin{array}{c}\text { Wadden et al } \\
\text { (1997) }\end{array}$ & $\begin{array}{c}\mathrm{N}=28 \text { obese } \\
\text { females } \\
(\mathrm{BMI} 36.5 \pm 5.1)\end{array}$ & $\begin{array}{l}\text { To determine the } \\
\text { changes in body } \\
\text { composition, resting } \\
\text { energy expenditure } \\
\text { (REE), appetite and } \\
\text { mood during a } 48 \text {-week } \\
\text { diet and exercise } \\
\text { program }\end{array}$ & $\begin{array}{l}\text { Appetite, hunger, satiety, } \\
\text { preoccupation with eating, and } \\
\text { intensity of food cravings } \\
\text { (Visual analogue scales) } \\
\text { Intervention: diet alone; } \\
\text { diet plus aerobic training } \\
\text { (moderate intensity, } 40 \text { min); } \\
\text { diet plus strength training ( }>14 \\
\text { repetitions for two sets, } 40 \\
\text { min); and diet plus aerobic } \\
\text { and strength training ( } 40 \mathrm{~min} \text {, } \\
60 \% \text { strength, } 40 \% \text { aerobic) }\end{array}$ & $\begin{array}{l}\text { No significant differences } \\
\text { among the exercisers and the } \\
\text { non-exercisers } \\
\text { Significant reductions in hunger } \\
\text { (beginning at week 5) and } \\
\text { preoccupation with food (only at } \\
\text { week } 5 \text { ) compared with baseline } \\
\text { Exercisers tended to report } \\
\text { greater consumption of excess } \\
\text { calories than did non-exercisers }\end{array}$ \\
\hline
\end{tabular}


Table 3. Dietary Restraint in Non Exercise and Exercise Situations

\begin{tabular}{|c|c|c|c|c|}
\hline $\begin{array}{l}\text { AUTHOR(S) } \\
\text { AND YEAR }\end{array}$ & SUBJECTS & OBJECTIVE & $\begin{array}{l}\text { VARIABLES MEASURED/ } \\
\text { INTERVENTION }\end{array}$ & RESULTS \\
\hline \multicolumn{5}{|c|}{ IN NON EXERCISE SITUATIONS } \\
\hline $\begin{array}{c}\text { Herman and } \\
\text { Mack } \\
\text { (1975) }\end{array}$ & $\begin{array}{c}\mathrm{N}=45 \text { normal } \\
\text { weight and obese } \\
\text { females } \\
\text { Restrained and } \\
\text { Unrestrained }\end{array}$ & $\begin{array}{l}\text { To examine } \\
\text { restraint as an } \\
\text { important } \\
\text { behavioral } \\
\text { mechanism } \\
\text { affecting the } \\
\text { expression of } \\
\text { hunger }\end{array}$ & $\begin{array}{l}\text { Degree of restraint } \\
\text { (Eating habit questionnaire) } \\
\text { Intervention: three pre-load } \\
\text { conditions: } 0,1 \text { or } 2 \text { milkshakes } \\
\text { Plus ad libitum intake from } 3 \\
\text { different ice cream flavors }\end{array}$ & $\begin{array}{l}\text { Obese subjects were not } \\
\text { significantly more } \\
\text { restrained than the normal } \\
\text { weight subjects } \\
\text { High restraint eaters } \\
\text { consumed more ice cream } \\
\text { after the milkshake pre-load } \\
(1 \text { or } 2) \text { than after no pre- } \\
\text { load at all }\end{array}$ \\
\hline $\begin{array}{l}\text { Weber et al } \\
\text { (1988) }\end{array}$ & $\begin{array}{c}\mathrm{N}=112 \text { normal } \\
\text { weight } \\
\text { (<15\% above } \\
\text { ideal weight) and } \\
\text { overweight } \\
\text { (>15\% above } \\
\text { their ideal } \\
\text { weight) females } \\
\text { Restrained and } \\
\text { Unrestrained }\end{array}$ & $\begin{array}{l}\text { To evaluate the } \\
\text { effects of level of } \\
\text { restraint, dietary } \\
\text { intake and obesity } \\
\text { on both immediate } \\
\text { and subsequent } \\
\text { self-reported } \\
\text { dietary intake }\end{array}$ & $\begin{array}{c}\text { Chronic dieting status } \\
\text { ("Concern for Dieting" and "Weight } \\
\text { Fluctuation" factors of the Revised } \\
\text { Restraint Scale of Herman and Polivy) } \\
\text { Intervention: pre-load condition: } 1 / 2 \text { of } \\
\text { the subjects received the } 10-\mathrm{oz} \text {. } \\
\text { milkshake; the other } 1 / 2 \text { did not receive } \\
\text { the pre-load } \\
\text { Plus ad libitum intake from } 3 \text { different } \\
\text { potato chip flavors }\end{array}$ & $\begin{array}{l}\text { ND-LR overweight and } \\
\text { obese subjects consumed } \\
\text { significantly more calories } \\
\text { than normal weight ND-LR } \\
\text { D-HR with pre-load } \\
\text { consumed significantly } \\
\text { more than LR-D } \\
\text { ND with a pre-load ate } \\
\text { less than ND with no pre- } \\
\text { load } \\
\text { HR eaters ate fewer } \\
\text { calories than LR } \\
\text { counterparts with no pre- } \\
\text { load }\end{array}$ \\
\hline
\end{tabular}


Table 3. Dietary Restraint in Non Exercise and Exercise Situations

\begin{tabular}{|c|c|c|c|c|}
\hline $\begin{array}{l}\text { AUTHOR(S) } \\
\text { AND YEAR }\end{array}$ & SUBJECTS & OBJECTIVE & $\begin{array}{l}\text { VARIABLES MEASURED/ } \\
\text { INTERVENTION }\end{array}$ & RESULTS \\
\hline \multicolumn{5}{|c|}{ IN NON EXERCISE SITUATIONS CONTINUED } \\
\hline $\begin{array}{c}\text { Kirschenbaum } \\
\text { and Dykman } \\
(1998)\end{array}$ & $\begin{array}{c}\mathrm{N}=80 \text { normal } \\
\text { weight (BMI } \\
\text { 19.1-25.8) and } \\
\text { overweight } \\
\text { (BMI 27.3-32.2) } \\
\text { females }\end{array}$ & $\begin{array}{c}\text { To identify } \\
\text { psychological } \\
\text { characteristics and } \\
\text { eating behaviors } \\
\text { associated with } \\
\text { weight cycling and } \\
\text { binge eating } \\
\text { behaviors in } \\
\text { overweight women }\end{array}$ & $\begin{array}{c}\text { Restraint eating, disinhibition, hunger } \\
\text { (Revised Restraint Scale of Herman and } \\
\text { Polivy) } \\
\text { Self-control skills } \\
\text { (Self-Control Schedule) } \\
\text { Intervention: "pre-load + taste test" } \\
\text { paradigm }\end{array}$ & $\begin{array}{l}\text { After the pre-load, the } \\
\text { restrained eaters with high } \\
\text { self-control skills ate } 128 \% \\
\text { more ice cream than their } \\
\text { LSCS counterparts (and } \\
\text { more than both groups of } \\
\text { the unrestrained subjects) }\end{array}$ \\
\hline $\begin{array}{l}\text { Lawson et al } \\
\quad(1995)\end{array}$ & $\begin{array}{l}\mathrm{N}=44 \\
\text { premenopausal } \\
\text { normal weight } \\
\text { (BMI 21) and } \\
\text { overweight } \\
\text { (BMI 33) } \\
\text { females }\end{array}$ & $\begin{array}{l}\text { To investigate the } \\
\text { influences of } \\
\text { dietary restraint } \\
\text { and disinhibition } \\
\text { upon: eating } \\
\text { behavior, } \\
\text { nutritional intake, } \\
\text { EE and body } \\
\text { composition }\end{array}$ & $\begin{array}{c}\text { Restraint eating, disinhibition, hunger } \\
\text { (TFEQ) } \\
\text { Binge Eating/Bulimic Behavior } \\
\text { (Bulimia Test) } \\
\text { Problematic eating } \\
\text { (Eating Attitude Test, Eating Disorder } \\
\text { Inventory) } \\
\text { EI } \\
\text { (Nutritional Diaries) } \\
\text { Activity measurement } \\
\text { (CALTRAC) }\end{array}$ & $\begin{array}{l}\text { High disinhibition (HD) } \\
\text { scores associated with } \\
\text { higher perceived hunger, } \\
\text { more bulimic symptoms, } \\
\text { more frequent subjective } \\
\text { episodes of overeating and } \\
\text { more frequent weight } \\
\text { cycling } \\
\text { HD coupled with LR } \\
\text { was associated with higher } \\
\text { adiposity, lower thermic } \\
\text { effect of food and reduced } \\
\text { PA }\end{array}$ \\
\hline
\end{tabular}


Table 3. Dietary Restraint in Non Exercise and Exercise Situations

\begin{tabular}{|c|c|c|c|c|}
\hline $\begin{array}{l}\text { AUTHOR(S) } \\
\text { AND YEAR }\end{array}$ & SUBJECTS & OBJECTIVE & $\begin{array}{l}\text { VARIABLES MEASURED/ } \\
\text { INTERVENTION }\end{array}$ & RESULTS \\
\hline \multicolumn{5}{|c|}{ IN NON EXERCISE SITUATIONS CONTINUED } \\
\hline $\begin{array}{l}\text { Lindroos et al } \\
\qquad(1997)\end{array}$ & $\begin{array}{l}\mathrm{N}=179 \text { obese } \\
(\mathrm{BMI}>32) \text { and } \\
147 \text { non-obese } \\
(\mathrm{BMI}<28) \\
\text { women }\end{array}$ & $\begin{array}{l}\text { To determine } \\
\text { which factors of } \\
\text { the TFEQ are } \\
\text { associated with } \\
\text { obesity and to } \\
\text { determine their the } \\
\text { correlations } \\
\text { between } \\
\text { nutritional } \\
\text { variables }\end{array}$ & $\begin{array}{c}\text { Restraint eating, disinhibition, hunger } \\
\text { (TFEQ) } \\
\text { Nutritional variables } \\
\text { (Self-administered dietary } \\
\text { questionnaire) }\end{array}$ & $\begin{array}{c}\text { High disinhibition (HD) } \\
\text { associated with obesity } \\
\text { and higher energy intakes in } \\
\text { the obese women } \\
\text { Disinhibition was the } \\
\text { strongest TFEQ factor } \\
\text { differentiating obese and } \\
\text { non-obese } \\
\text { Within the obese sample, } \\
\text { negative association } \\
\text { between dietary restraint } \\
\text { and EI } \\
\text { No such associations were } \\
\text { observed within the non- } \\
\text { obese }\end{array}$ \\
\hline \multicolumn{5}{|c|}{ IN EXERCISE SITUATIONS } \\
\hline $\begin{array}{l}\text { Tepper et al } \\
\text { (1996) }\end{array}$ & $\begin{array}{c}\mathrm{N}=249 \text { young } \\
\text { normal weight } \\
\text { females } \\
\text { (BMI 19.1-25.8) } \\
\text { and males } \\
\text { (BMI 20.7-26.4) } \\
\text { Restrained and } \\
\text { Unrestrained }\end{array}$ & $\begin{array}{l}\text { To understand the } \\
\text { relationship } \\
\text { between diet and } \\
\text { physical activity in } \\
\text { restrained }(\mathrm{R}) \text { and } \\
\text { unrestrained (U) } \\
\text { eaters }\end{array}$ & $\begin{array}{c}\text { Self-reported activity questionnaires and } \\
\text { the TFEQ }\end{array}$ & $\begin{array}{l}\text { Similar EI and PA between } \\
\text { the } \mathrm{R} \text { and } \mathrm{U} \text { eaters } \\
\text { Physically active- } \mathrm{R} \text { females } \\
\text { consumed more } \\
\text { carbohydrates and } \\
\text { significantly }(13.3 \%) \text { less } \\
\text { fat than their U counterparts }\end{array}$ \\
\hline
\end{tabular}


Table 3. Dietary Restraint in Non Exercise and Exercise Situations

\begin{tabular}{|c|c|c|c|c|}
\hline $\begin{array}{l}\text { AUTHOR(S) } \\
\text { AND YEAR }\end{array}$ & SUBJECTS & OBJECTIVE & $\begin{array}{l}\text { VARIABLES MEASURED/ } \\
\text { INTERVENTION }\end{array}$ & RESULTS \\
\hline \multicolumn{5}{|c|}{ IN EXERCISE SITUATIONS CONTINUED } \\
\hline $\begin{array}{l}\text { King et al } \\
\text { (1996) }\end{array}$ & $\begin{array}{c}\mathrm{N}=13 \text { normal } \\
\text { weight females } \\
\text { (BMI } 21.9 \pm 1.6) \\
\text { age }=22.6 \pm 2.3 \\
\text { Unrestrained }\end{array}$ & $\begin{array}{l}\text { To examine the } \\
\text { short term effects } \\
\text { of exercise and } \\
\text { diet composition } \\
\text { on appetite in } \\
\text { unrestrained } \\
\text { females }\end{array}$ & $\begin{array}{c}\text { Stationary cycling } \\
\text { Four interventions: } \\
\text { Rest (45 min)- high-fat/low-CHO, } \\
\text { Rest (45 min)- low-fat/high-CHO, } \\
\text { Exercise }\left(70 \% \text { VO }{ }^{2} \text { max, } 50 \text { min)- }\right. \\
\text { HF/LC, } \\
\left.\text { Exercise( } 70 \% \mathrm{VO}^{2} \text { max, } 50 \mathrm{~min}\right)- \\
\text { LF/HC } \\
\text { Standardized breakfast and ad libitum } \\
\text { test meal } 15 \text { minutes post } \\
\text { Sensory assessment of foods measured } \\
\text { post meals } \\
\text { TFEQ }\end{array}$ & $\begin{array}{l}\text { No significant difference in } \\
\text { hunger suppression between } \\
\text { exercise and rest nor } \\
\text { between lunch types } \\
\text { No significant effect of } \\
\text { exercise on short term } \\
\text { energy or macronutrient } \\
\text { intake } \\
\text { Significant effect of } \\
\text { exercise on palatability of } \\
\text { foods }\end{array}$ \\
\hline $\begin{array}{l}\text { Lluch et al } \\
\text { (1997) }\end{array}$ & $\begin{array}{c}\mathrm{N}=12 \text { normal } \\
\text { weight females } \\
\text { (BMI 22.6 } \\
\text { age }=19-97 \\
\text { age }=21.7 \pm 2.2 \\
\text { Restrained }\end{array}$ & $\begin{array}{l}\text { To investigate the } \\
\text { short term effects } \\
\text { of exercise and } \\
\text { diet composition } \\
\text { on appetite control } \\
\text { in restrained } \\
\text { females }\end{array}$ & $\begin{array}{c}\text { Stationary cycling } \\
\text { Four interventions: } \\
\text { Rest (50 min)-LF, } \\
\text { Rest ( } 50 \text { min)-HF, } \\
\left.\text { Exercise ( } 70 \% \mathrm{VO}^{2} \mathrm{max}, 50 \mathrm{~min}\right)-\mathrm{LF}, \\
\left.\text { Exercise( } 70 \% \mathrm{VO}^{2} \mathrm{max}, 50 \mathrm{~min}\right)-\mathrm{HF} \\
\text { Standardized breakfast and ad libitum } \\
\text { lunch ( } 20 \text { minutes post), dinner and } \\
\text { snack test meals } \\
\text { Motivation to eat, mental states and post } \\
\text { meal hedonic feelings measured } \\
\text { TFEQ }\end{array}$ & $\begin{array}{l}\text { Significant effect of } \\
\text { exercise on tastiness and } \\
\text { pleasantness of the LF foods } \\
\text { served at lunch but did not } \\
\text { induce disinhibition of } \\
\text { restraint } \\
\text { No significant effect of } \\
\text { exercise on hunger or EI }\end{array}$ \\
\hline
\end{tabular}


Table 3. Dietary Restraint in Non Exercise and Exercise Situations

\begin{tabular}{|c|c|c|c|c|}
\hline $\begin{array}{c}\text { AUTHOR(S) } \\
\text { AND YEAR }\end{array}$ & SUBJECTS & OBJECTIVE & $\begin{array}{l}\text { VARIABLES MEASURED/ } \\
\text { INTERVENTION }\end{array}$ & RESULTS \\
\hline \multicolumn{5}{|c|}{ IN EXERCISE SITUATIONS CONTINUED } \\
\hline $\begin{array}{c}\text { George and } \\
\text { Morganstein } \\
(\mathbf{2 0 0 0 )}\end{array}$ & $\begin{array}{c}\mathrm{N}=24 \text { normal } \\
\text { weight } \\
\text { (BMI 22 } \pm \text { 1) and } \\
\text { overweight } \\
\text { (BMI 28 } \pm \mathbf{1} \text { ) } \\
\text { females } \\
\text { age }=35 \pm 8 \\
\text { Restrained and } \\
\text { Unrestrained }\end{array}$ & $\begin{array}{l}\text { To determine the } \\
\text { relationship } \\
\text { between level of } \\
\text { dietary restraint } \\
\text { and PE-EI }\end{array}$ & $\begin{array}{c}\text { Treadmill walking } \\
\text { Single one-hour bout of moderate } \\
\text { intensity exercise } \\
\text { PE-EI (lunch) and 24-hour EI } \\
\text { TFEQ }\end{array}$ & $\begin{array}{l}\text { PE-EI in the women } \\
\text { identified as high DR was } \\
\text { greater than that of the } \\
\text { women identified as low } \\
\text { DR } \\
\text { No significant } \\
\text { difference in PE-EI in } \\
\text { reference to BMI }\end{array}$ \\
\hline $\begin{array}{l}\text { Kleim et al } \\
\quad(1996)\end{array}$ & $\begin{array}{c}\mathrm{N}=15 \text { reduced- } \\
\text { obese women } \\
\text { (BMI 29) }\end{array}$ & $\begin{array}{l}\text { To investigate the } \\
\text { effect of exercise, } \\
\text { cognitive restraint, } \\
\text { disinhibition and } \\
\text { hunger on self- } \\
\text { selected food } \\
\text { intake }\end{array}$ & $\begin{array}{c}\text { Two Interventions: } \\
\text { Moderate intensity aerobic exercise } \\
\text { (treadmill walking at } \mathrm{VO}^{2} \text { max for } 29- \\
55 \mathrm{~min} \text { ), } \\
\text { Low resistance weight training } \\
\text { 24 hour EI for fourteen consecutive days } \\
\text { Eating Inventory }\end{array}$ & $\begin{array}{l}\text { No significant increase } \\
\text { in EI with both exercise } \\
\text { treatments (aerobic and } \\
\text { weight training) compared } \\
\text { to the non-exercise days } \\
\text { Regardless of exercise, } \\
\text { seven subjects consistently } \\
\text { consumed energy in excess } \\
\text { and the other eight, } \\
\text { restricted their EI } \\
\text { Higher disinhibition and } \\
\text { hunger scores contributed } \\
\text { significantly to this between } \\
\text { subject variance in EI. }\end{array}$ \\
\hline
\end{tabular}


Table 4. A Model of Dietary Restraint and Post Exercise Energy Intake

\begin{tabular}{|c|c|c|c|c|}
\hline \multirow{11}{*}{$\begin{array}{c}\uparrow \\
\text { PHYSICAL } \\
\text { ACTIVITY }\end{array}$} & $\begin{array}{c}\text { LEVEL OF } \\
\text { DIETARY } \\
\text { RESTRAINT }\end{array}$ & $\begin{array}{c}\text { BODY } \\
\text { WEIGHT }\end{array}$ & $\begin{array}{l}\text { DIETING } \\
\text { STATUS }\end{array}$ & $\begin{array}{l}\text { EI COMPARED TO NON } \\
\text { EXERCISE PERIOD }\end{array}$ \\
\hline & \multirow{4}{*}{ Restrained } & \multirow{2}{*}{ Lean } & Currently Dieting & $=/ \downarrow$ \\
\hline & & & Not Currently Dieting & $=$ \\
\hline & & \multirow[b]{2}{*}{ Overweight } & Currently Dieting & $=/ \downarrow$ \\
\hline & & & Not Currently Dieting & $=$ \\
\hline & \multirow[t]{2}{*}{ Unrestrained } & Lean & - & $\uparrow$ \\
\hline & & Overweight & - & $=$ \\
\hline & \multirow{4}{*}{ Disinhibited } & \multirow[b]{2}{*}{ Lean } & $\begin{array}{c}\text { Currently Dieting } \\
\text { (Period of restraint eating) }\end{array}$ & $=/ \downarrow$ \\
\hline & & & $\begin{array}{c}\text { Not Currently Dieting } \\
\text { (Period of uncontrolled eating) }\end{array}$ & $\uparrow$ \\
\hline & & \multirow{2}{*}{ Overweight } & $\begin{array}{c}\text { Currently Dieting } \\
\text { (Period of restraint eating) }\end{array}$ & $=/ \downarrow$ \\
\hline & & & $\begin{array}{l}\text { Not Currently Dieting } \\
\text { (Period of uncontrolled eating) }\end{array}$ & $\uparrow$ \\
\hline
\end{tabular}


Table 5. Perceived Energy Intake and its Effect on Post Exercise Energy Intake

\begin{tabular}{|c|c|c|c|c|}
\hline $\begin{array}{l}\text { AUTHOR(S) } \\
\text { AND YEAR } \\
\end{array}$ & SUBJECTS & OBJECTIVE & $\begin{array}{l}\text { VARIABLES MEASURED/ } \\
\text { INTERVENTION }\end{array}$ & RESULTS \\
\hline $\begin{array}{l}\text { Wooley et al } \\
\text { (1972) }\end{array}$ & $\begin{array}{c}\mathrm{N}=7 \text { obese } \\
\text { (at least } 18 \% \text { above } \\
\text { their ideal weight) } \\
\text { and } 7 \text { non-obese } \\
\text { (within } 10 \% \text { of ideal } \\
\text { body weight) males } \\
\text { and females }\end{array}$ & $\begin{array}{l}\text { To determine if } \\
\text { subjects can } \\
\text { perceive } \\
\text { (metabolically) } \\
\text { excess or deficit of } \\
\text { calories above or } \\
\text { below their usual } \\
\text { caloric intake, and if } \\
\text { this affects hunger } \\
\text { and satiety }\end{array}$ & $\begin{array}{c}\text { Hunger } \\
\text { (7-point hunger scale) } \\
\text { "Caloric judgements" } \\
\text { Intervention: high-calorie }(1.07 \\
\mathrm{cal} / \mathrm{cc}) \text { and low-calorie }(0.57 \\
\mathrm{kcal} / \mathrm{cc}) \text { liquid meals for breakfast } \\
\text { or lunch } \\
\text { Plus the subjects indicated } \\
\text { whether they thought the meal was } \\
\text { high calorie or low calorie }\end{array}$ & $\begin{array}{l}\text { Individuals had almost no } \\
\text { ability to correctly identify } \\
\text { the meals as high or low } \\
\text { calorie } \\
\text { Hunger was highly } \\
\text { related to the "judged" } \\
\text { caloric content of the test } \\
\text { meal }\end{array}$ \\
\hline $\begin{array}{l}\text { Ogden and } \\
\text { Wardle } \\
\text { (1990) }\end{array}$ & $\begin{array}{c}\mathrm{N}=\mathbf{2 0} \text { females } \\
\text { Restrained and } \\
\text { Unrestrained }\end{array}$ & $\begin{array}{c}\text { To study the effect } \\
\text { of cognitive restraint } \\
\text { on the sensitivity to } \\
\text { internal } \\
\text { (physiological) and } \\
\text { external (cognitive } \\
\text { and emotional) cues } \\
\text { of hunger and satiety }\end{array}$ & $\begin{array}{c}\text { Cognitive restraint } \\
\text { (Restrained Eating Scale of the } \\
\text { Dutch Eating Behavior } \\
\text { Questionnaire) } \\
\text { Hunger and satiety } \\
\text { (Visual analogue scales) } \\
\text { Intervention: high calorie ( } 300 \\
\text { kcal) or low calorie (50 kcal) drink } \\
\text { Plus they were either correctly or } \\
\text { incorrectly told its calorie content }\end{array}$ & $\begin{array}{l}\text { Greater decrease in hunger } \\
\text { and increase in fullness after } \\
\text { the high calorie drink than } \\
\text { after the low calorie drink } \\
\text { HR subjects' EI was } \\
\text { almost the same irrespective } \\
\text { of the believed caloric } \\
\text { intake of the drink } \\
\text { in comparison to the HR } \\
\text { eaters, the LR eaters } \\
\text { consumed significantly } \\
\text { more at the test meal, } \\
\text { irrespective of the condition }\end{array}$ \\
\hline
\end{tabular}


Table 5. Perceived Energy Intake and its Effect on Post Exercise Energy Intake

\begin{tabular}{|c|c|c|c|c|}
\hline $\begin{array}{l}\text { AUTHOR(S) } \\
\text { AND YEAR }\end{array}$ & SUBJECTS & OBJECTIVE & $\begin{array}{l}\text { VARIABLES MEASURED/ } \\
\text { INTERVENTION }\end{array}$ & RESULTS \\
\hline $\begin{array}{l}\text { Huon et al } \\
\text { (1972) }\end{array}$ & $\begin{array}{c}\mathrm{N}=56 \text { normal } \\
\text { weight females } \\
\text { (BMI 22.6 } \pm 3.9 \text { ) } \\
\text { Restrained and } \\
\text { unrestrained }\end{array}$ & $\begin{array}{l}\text { To study the role of } \\
\text { restraint and } \\
\text { disinhibition in appetite } \\
\text { control }\end{array}$ & $\begin{array}{c}\text { Restraint } \\
\text { (TFEQ) } \\
\text { Desire for food and willingness } \\
\text { to eat } \\
\text { Intervention: high CHO } \\
(74 \%) \text { or low CHO (44\%) } \\
\text { breakfast with equal caloric } \\
\text { content } \\
\text { Plus subjects were correctly } \\
\text { or incorrectly told its CHO } \\
\text { content } \\
\text { Ad libitum test meal provided } \\
4 \text { hours later }\end{array}$ & $\begin{array}{l}\text { LR eaters ate significantly } \\
\text { more after the } 74 \% \text { than the } \\
44 \% \text { CHO breakfast } \\
\text { HR ate more after } \\
\text { having the } 44 \% \text { than the } \\
74 \% \text { CHO breakfast, and ate } \\
\text { less when they knew they } \\
\text { had eaten a higher } \\
\text { proportion of CHO } \\
\text { HR eaters showed a } \\
\text { decrease in their appetite } \\
\text { and EI after having the high } \\
\text { CHO breakfast }\end{array}$ \\
\hline $\begin{array}{l}\text { Knight and } \\
\text { Boland } \\
\text { (1989) }\end{array}$ & $N=250$ females & $\begin{array}{c}\text { To evaluate the } \\
\text { influence of perceived } \\
\text { calories and food types } \\
\text { in the eating patterns } \\
\text { college females }\end{array}$ & See studies 1-3 & See studies $1-3$ \\
\hline Study \#1 & $\begin{array}{c}\mathrm{N}=\mathbf{8 4} \text { females } \\
\text { Restrained and } \\
\text { unrestrained }\end{array}$ & $\begin{array}{l}\text { To document the } \\
\text { association between } \\
\text { restraint and avoidance } \\
\text { of certain foods }\end{array}$ & $\begin{array}{c}\text { Restraint } \\
\text { (Revised Restraint Scale of } \\
\text { Herman and Polivy) } \\
\text { Dietary permitted/forbidden } \\
\text { foods } \\
\text { (9-point scale) }\end{array}$ & $\begin{array}{l}\text { HR eaters evaluated a } \\
\text { larger number of foods as } \\
\text { forbidden (foods that they } \\
\text { believed should be avoided } \\
\text { on a weight reduction diet) } \\
\text { than the LR eaters }\end{array}$ \\
\hline
\end{tabular}


Table 5. Perceived Energy Intake and its Effect on Post Exercise Energy Intake

\begin{tabular}{|c|c|c|c|c|}
\hline $\begin{array}{l}\text { AUTHOR(S) } \\
\text { AND YEAR }\end{array}$ & SUBJECTS & OBJECTIVE & $\begin{array}{l}\text { VARIABLES MEASURED/ } \\
\text { INTERVENTION }\end{array}$ & RESULTS \\
\hline Study \#2 & $\begin{array}{c}\mathrm{N}=93 \text { nomral } \\
\text { weight females } \\
(<120 \% \text { maximum } \\
\text { weight in } \\
\text { recommended } \\
\text { range }) \\
\text { Restrained and } \\
\text { unrestrained }\end{array}$ & $\begin{array}{c}\text { To examine the } \\
\text { separate effects of } \\
\text { caloric value and food } \\
\text { type } \\
\text { (permitted/forbidden) } \\
\text { on eating behaviors }\end{array}$ & $\begin{array}{c}\text { Restraint } \\
\text { Intervention: five pre-load } \\
\text { conditions: no pre-load; } \\
\text { forbidden pre-load: } 1 \text { milkshake } \\
\text { (290 kcal), } 2 \text { milkshakes ( } 580 \\
\text { kcal); permitted pre-load: } 1 \\
\text { bowl cottage cheese ( } 290 \mathrm{kcal}) \text {, } \\
2 \text { bowls cottage cheese ( } 580 \\
\text { kcal) } \\
\text { Plus ad libitum intake from } 3 \\
\text { different ice cream flavors }\end{array}$ & $\begin{array}{l}\text { HR eaters ate more of a test } \\
\text { meal (three flavors of ice } \\
\text { cream) following a } \\
\text { "forbidden food" pre-load } \\
\text { (ice cream) than following a } \\
\text { "permitted food" pre-load } \\
\text { (cottage cheese) of } \\
\text { equivalent caloric content. }\end{array}$ \\
\hline Study \#3 & $\begin{array}{c}\mathrm{N}=73 \text { nomral } \\
\text { weight females } \\
(<120 \% \text { maximum } \\
\text { weight in } \\
\text { recommended } \\
\text { range }) \\
\text { Restrained and } \\
\text { unrestrained }\end{array}$ & $\begin{array}{l}\text { To examine the effect } \\
\text { of anticipated } \\
\text { (expected) } \\
\text { consumption on the } \\
\text { restraint eating pattern } \\
\text { and the amount of food } \\
\text { eaten during a test meal }\end{array}$ & $\begin{array}{c}\text { Restraint } \\
\text { Intervention: five anticipatory } \\
\text { conditions, expecting to eat: } \\
\text { nothing; high calorie, forbidden } \\
\text { (400 kcal, milkshake); low } \\
\text { calorie, forbidden ( } 150 \mathrm{kcal} \text {, ice } \\
\text { cream bar); high calorie, } \\
\text { permitted (400 kcal, chef's } \\
\text { salad); low calorie, permitted } \\
\text { (150 kcal, vegetable salad) } \\
\text { Plus ad libitum intake from } 3 \\
\text { different crackers }\end{array}$ & $\begin{array}{l}\text { HR eaters ate more of the } \\
\text { test meal when they } \\
\text { anticipated a forbidden food } \\
\text { than when they anticipated a } \\
\text { permitted food, when } \\
\text { compared to the LR eaters. } \\
\text { HR subjects who expected } \\
\text { to eat a low calorie } \\
\text { forbidden food ate almost } \\
\text { twice as much of the test } \\
\text { meal than when they } \\
\text { expected to eat a permitted } \\
\text { food with the same caloric } \\
\text { content }\end{array}$ \\
\hline
\end{tabular}




\section{REFERENCES}

1. Kissilef HR, Pi-Sunyer FX, Segal K. Acute effects of exercise on food intake in obese and non-obese women. Am J Clin Nutr. 1990;52:240-5.

2. King NA. What processes are involved in the appetite responses to moderate increase in exercise-induced energy expenditure? Proc Nutr Soc. 1999;58:107-13.

3. Woo R, Garrow JS, Pi-Sunyer FX. Effect of exercise on spontaneous calorie intake in obesity. Am J Clin Nutr. 1982;36:470-7.

4. Woo R, Garrow JS, Pi-Sunyer FX. Voluntary food intake during prolonged exercise in obese women. Am J Clin Nutr. 1982;36:478-84.

5. Durrant ML, Royston JP, Wloch RT. Effects of exercise on energy intake and eating patterns in lean and obese humans. Physiol Behav. 1982;29:449-54.

6. Stunkard AJ, Messick S. The three-factor eating questionnaire to measure dietary restraint, disinhibition and hunger. $J$ Psychosom Res 1985;29:71-83.

7. Carmody TP, Brunner RL, St-Jeor ST. Dietary helplessness and disinhibition in weight cyclers and weight maintainers. Int J Eat Disord. 1995;18:247-56.

8. Hollis JF, Carmody TP, Connor SL, Fey SG, Matarazzo JD. The Nutrition Attitude Survey: Association with dietary habits, psychological and physical wellbeing, and coronary risk factors. Health Psychol. 1986;5:359-74.

9. Foster GD, Wadden TA, Kendall PC, Stunkard AJ, Vogt RA. Psychological effects of weight loss and regain: a prospective evaluation. J Consult Clin Psychol. 1996;64:752-7.

10. McGuire MT, Wing RR, Klem ML, Lang W, Hill JO. What predicts weight regain in a group of successful weight losers? J Consult Clin Psychol. 1999;67:177-85. 
11. Klesges RC, Isbell TR, Klesges LM. Relationship between dietary restraint, energy intake, physical activity and body weight: A prospective analysis. J Abnorm Psychol. 1992;101:668-74.

12. Tiggeman M. Dietary restraint as a predictor of reported weight loss and affect. Psychol Rep. 1994;75:1679-82.

13. Folgelholm M, Kukkonen-Harjula K, Oja P. Eating Control and physical activity as determinants of short-term weight maintenance after a very-low-calorie diet among obese women. Int J Obes Relat Metab Disord. 1999;23:203-10.

14. Wadden TA, Vogt RA, Andersen RE, et al. Exercise in the treatment of obesity: effects of four interventions on body composition, resting energy expenditure, appetite and mood. J Consult Clin Psychol. 1997;65:269-77.

15. Herman CP, Polivy J. Restrained eating. In: Stunkard AJ, ed. Obesity. Philadelphia: WB Saunders; 1980:208-225.

16. Blanchard FA, Frost RO. Two factors of restraint: Concern for dieting and weight fluctuation. Behav Res Ther. 1983;3:259-267.

17. Johnson WG, Lake L, Mahan M. Restrained eating: Measuring an elusive construct. Addict Behav. 1984;8:413-418.

18. Heatherton TF, Herman CP, Polivy J, King GA, McGree ST. The (mis)measurements of restraint: an analysis of conceptual and psychometric issues. $J$ Abnorm Psychol. 1988;97: 19-28.

19. Ruderman, A J. Dietary Restraint: A Theoretical and Empirical Review. Psychol Bull. 1989;99:247-62.

20. Laessle RG, Tuschl, RJ, Kotthaus BC, Pirke KM. A comparison of validity of three scales for the assessment of dietary restraint. J Abnorm Psychol. 1989;98:504-7. 
21. Herman CP, Mack D. Restrained and unrestrained eating. J Pers. 1975;43:647-60.

22. Weber JM, Klesges RC, Klesges LM. Dietary restraint and obesity: Their effects on dietary intake. J Behav Med. 1988;11:185-99.

23. Kirschenbaum DS, Dykman BM. Disinhibited eating by resourceful restrained eaters. J Abnorm Psychol. 1991;100:227-30.

24. Lawson OJ, Williamson DA, Champagne CM, et al. The association of body weight, dietary intake and energy expenditure with dietary restraint and disinhibition. Obes Res. 1995;3:153-61.

25. Lowe MR. The effect of dieting on eating behavior: a three-factor model. Psychol Bull. 1993;114:100-21.

26. Lindross AK, Lissner L, Mathiassen ME, et al. Dietary intake in relation to retrained eating, disinhibition and hunger in reduced obese and nonobese Swedish women. Obes Res. 1997;5:175-82.

27. Tepper BJ, Trail AC, Shaffer SE. Diet and physical activity in restrained eaters. Appetite. 1996;27:51-64.

28. King NA, Snell L, Smithe RD, Blundell JE. Effects of short-term exercise on appetite responses in unrestrained females. Eur J Clin Nutr. 1996;50:663-7.

29. Lluch A, King NA, Blundell JE. Exercise in dietary restrained women: No effect on energy intake but change in hedonic ratings. Eur J Clin Nutr. 1998;52:300-7.

30. Llutch A, King NA, Blundell JE. No energy compensation at the meal following exercise in dietary restrained and unrestrained women. Br J Nutr. 2000;4:219-25.

31. Tremblay A, Almeras N, Boer J, Kranenbarg EK, Despres JP. Diet composition and post-exercise energy balance. Am J Clin Nutr. 1994;59:975-9. 
32. Hill JO, Melby C, Johnson SL, Peters JC. Physical activity and energy requirements. Am J Clin Nutr. 1995;62(suppl): 1059S-66.

33. Kleim NL, Canty DJ, Barbieri TF, Wu MM. Effect of exercise and dietary restraint on energy intake of reduced obese women. Appetite. 1996;26:55-70.

34. Rogers, PJ. Eating habits and appetite control: a psychobiological perspective. Proc Nutr Soc. 1999;58:59-67.

35. Wooley OW, Wooley SC, Dunham RB. Can calories be perceived and do they affect hunger in obese and non-obese humans? J Comp Physiol Psychol. 1972;80:250-8.

36. Ogden J, Wardle $\mathbf{J}$. Cognitive restraint and sensitivity to cues for hunger and satiety. Physiol Behav. 1990;47:477-81.

37. Huon GF, Wooton M, Brown LB. The role of restraint and disinhibition in appetite control. J Psychosom Res 1991;35:49-58.

38. Knight LJ, Boland FJ. Restrained eating: An experimental disentanglement of the disinhibiting variables of perceived calories and food type. $J$ Abnorm Psychol. 1989;98: 412-20.

39. Woo R, Pi-Sunyer FX. Effect of increased physical activity on voluntary intake in lean women. Metabolism. 1982;34:836-41.

40. Canty, DJ. The effects of exercise, diet and eating restraint factors on appetite, emotions, and dietary intake in reduced-obese women. Dissert Abstr Int.: Section B: The Sciences \& Engeneering, Vol 58 (10-B), Apr 1998, 5333. 
MANUSCRIPT

THE IMPACT OF DIETING STATUS AND RESTRAINT ON

POST-EXERCISE ENERGY INTAKE IN OVERWEIGHT FEMALES

\section{INTRODUCTION}

Exercise has been acclaimed as an important component of weight reduction and weight management programs, especially when combined with healthy eating habits (i.e. low energy/low fat diets) (1-3). The American College of Sports Medicine has stated that low to moderate levels of exercise may be enough for sedentary individuals to obtain significant health benefits, including weight loss and cardio-respiratory fitness (4). Theoretically, exercise has the potential to impact body weight as it may elicit negative energy balance by increasing daily energy expenditure (EE). It has been suggested that exercise may effect $\mathrm{EE}$ through increasing resting metabolic rate (5-7). However, the effectiveness of exercise in relation to the energy balance equation and thus, in the prevention and treatment of overweight and obesity, is still not completely understood. Furthermore, some studies suggest that energy balance is predominantly influenced through the regulation of energy intake (EI) rather than EE through activity $(8,9)$. Understanding the relationship between exercise and food intake is a key issue in developing successful prescriptions for weight management.

Several studies have attempted to examine the relationship between exercise and food intake. The results of most of these studies and several recent review articles suggested that there is a weak, short-term coupling between exercise induced EE and post-exercise 
energy intake (PE-EI) (10-16). That is to say, exercise does not necessarily always precipitate an increase in EI, appetite and/or hunger. However, results from a few studies suggested the opposite (17-20). Discrepancies among these studies may be due to the variety of methodological and experimental designs that have been used.

Hill et al. (21) have theorized that an individual's dieting status as well as their cognitive approach to eating (i.e. dietary restraint and disinhibition) can affect PE-EI. Dietary restraint describes the degree to which an individual restricts his or her food intake. Disinhibition, in reference to dietary restraint, reflects the extent to which an individual feels loss of control in their effort to restrict food intake (22).

A few studies have investigated the relationship between dietary restraint and PE-EI. The results of a series of studies conducted by King et al. (23) and Lluch et al. (24) showed that among both normal weight restrained and unrestrained females an acute bout of high intensity exercise did not induce energy compensation. Therefore, they concluded that exercise could be used advantageously to control appetite and PE-EI in restrained and unrestrained normal weight females. However, no research has focused on the effect of dietary restraint coupled with dieting status (currently dieting or not) on PE-EI in overweight females.

To further understand these issues, in reference to energy balance, this study investigated the impact of dieting status (consciously dieting or not consciously dieting) and restraint of sedentary overweight women on PE-EI acutely and during the twelve hours after a 
bout of moderate intensity exercise. We hypothesized that overweight women who were currently dieting and had a high level of dietary restraint would significantly decrease their EI after a bout of moderate intensity physical activity, when compared to overweight women who were not dieting but varied in their level of dietary restraint.

\section{RESEARCH METHODS AND PROCEDURES}

\section{Participants}

Thirty-six overweight women (BMI 25-30) were recruited for this study. Recruitment took place at a university setting. Announcements explaining that participants were needed for an "exercise study" were sent out through flyers and e-mail messages. Individuals were encouraged to participate in the study by offering them two days of free lunch and a small monetary compensation $(\$ 10)$. The Institutional Review Board of Florida International University approved this study. All participants were required to sign an Informed Consent Form.

The participants, which included students, faculty and staff, were pre-screened for eligibility through a telephone interview. Eligibility requirements included: overweight (BMI 25-30) (self-reported weight and height); pre-menopausal; non-smoker; not pregnant or lactating; in good health - without chronic diseases or depression; and not taking any medications that could alter food intake. All the women had to be sedentary, meaning that they had not participated in aerobic physical activity ( 30 minutes per session) more than twice a week in the past six months. 
To test our hypothesis, the study design included 3 groups each with 12 participants. The three groups were: dieters with high restraint (D-HR); non-dieters with high restraint (ND-HR); and non-dieters with low restraint (ND-LR). In order to determine the dieting status of each participant, each participant was asked about her current dieting status during the initial telephone interview. The term "currently dieting" was defined "as actively/conscientiously trying to lose weight".

In order to determine the level of dietary restraint, prior to the beginning of the study each participants completed the Three-Factor Eating Questionnaire (TFEQ) (25). This 51-item questionnaire was used to measure three dimensions of dietary restraint: (a) cognitive restraint of eating; (b) disinhibition; and (c) susceptibility to hunger (25). High restraint was defined as a score of $>10$ and low restraint as a score of $\leq 10$. The highest possible scores for disinhibition and hunger were 16 and 14 , respectively.

\section{Study Design}

This study consisted of two experimental conditions, exercise (E) and non-exercise (NE) in a counterbalanced-crossover design on two different days ( 4 to 7 days apart). The participants were randomly assigned either to an E or NE condition and on the second day of the experiment the conditions were reversed. On the E day, the participants did moderate intensity exercise, walked on a treadmill at $60 \%-70 \%$ of their maximum heart rate (MHR) for 60 minutes. Heart rate was measured using a polar heart rate monitor (Polar Pacer ${ }^{8}$ ). The following formula was used to estimate the caloric expenditure of 60 minutes of moderate pace walking: $0.0175 \mathrm{kcal} \mathrm{kg}^{-1} / \mathrm{min}^{-1} / \mathrm{METS}^{-1} \times$ METS (3.5) $\mathrm{x}$ mean 
body weight ( $73 \mathrm{~kg}$ ) (26). On the NE day, the participants followed exactly the same procedures as the $\mathrm{E}$ day, except that they were asked to sit quietly for 60 minutes during which time they read, listened to music, studied, etc. The estimated the caloric expenditure of 60 minutes of rest was calculated with the following equation: $0.0175 \mathrm{kcal}$ $\mathrm{kg}^{-1} / \mathrm{min}^{-1} / \mathrm{METS}^{-1} \times$ METS (1.5) x mean body weight (73 kg) (26). After participation in the study, participants were debriefed using a follow up questionnaire (Appendix A).

Both the $\mathrm{E}$ and $\mathrm{NE}$ conditions were preceded by a standard breakfast at home (before 9:00 AM). The participants were advised that this breakfast should include the following food group servings: 2 breads ( $80 \mathrm{kcal} / \mathrm{each}), 1$ fruit $(60 \mathrm{kcal}), 1$ milk (optional) (120 $\mathrm{kcal}), 1$ meat $/$ meat substitute $(75 \mathrm{kcal}), 1$ fat $(45 \mathrm{kcal})$ and 2 sugars $(60 \mathrm{kcal} / \mathrm{each})$. Examples of each food group servings were provided to the participants (Appendix B). This ensured that all the participants had a uniform caloric intake $(\sim 500 \mathrm{kcal})$ before each experimental condition. Participants were asked to eat exactly the same breakfast for each experimental day.

On the E day, each subject (individually) came to the university fitness center at 10:00 AM and changed into their exercise clothes. They performed the exercise bout (from 10:30AM - 11:30AM) supervised by the investigator. After exercising, they were given time to cool down, shower (optional) and dress. Once they were ready (approximately 30 minutes after completion of the session), they were driven from the fitness center to the university cafeteria where they chose their lunch meal ad libitum from the various kiosks at this facility. The food available included a wide variety of choices ranging from fast 
food, sandwiches, salad/fruit buffet, hot buffet line, pastry, dairy products, etc. It was also possible to select individual items such as chips, sodas, fruit juices/smoothies, candy bars, cookies, ice cream, etc. All the participants began lunch between 12:30 PM-1:00 PM on both experimental days.

\section{Assessment of Lunch EI}

Lunch EI intake was determined by observing and recording the foods selected by each participant while they were engaged in making food choices. These observations were finalized once the participant and the investigator sat together at the table. The participants however, were not aware that their choices and food intake were being monitored. Once the participant had chosen her lunch, the investigator selected her own, trying to have a similar or even the same meal. When each participant had finished eating, the investigator offered to return the lunch tray to the tray station as a courtesy to the participant. The investigator took the tray to record and weigh any food items that had not been eaten to determine the actual food intake.

Information was obtained for the dietary analysis from the fast food franchises (i.e. websites) and other kiosks concerning pre-determined portion sizes/weights and caloric and macronutrient composition of the selected foods/meals. Nutritional values were obtained from the labels of pre-packaged foods and beverages. When necessary, identical food samples of participant's food choices were purchased by the investigator. With these samples, it was possible to determine the exact weights and ingredients of the selected foods/meals (i.e. combination foods). Nutritional analysis, quantitative and qualitative, 
was performed using the Nutritionist Five ${ }^{\mathrm{TM}}$ software (First Databank, Inc., San Bruno, CA).

\section{Assessment of 12-hour EI}

The 12-hour EI included the lunch meal plus everything the participant ate until bedtime of each experimental day. Following the lunch meal, the participants were taught how to record their food intake for the rest of each experimental day. The individual food logs was reviewed with the participants the following day. Food portions were confirmed using photographs from the American Dietetic publication "Portion Photos of Popular Foods" (27). Nutritional analysis was performed using the Nutritionist Five ${ }^{\mathrm{TM}}$ software (First Databank, Inc., San Bruno, CA).

\section{Assessment of Perceived EE and EI}

On both the $\mathrm{E}$ and NE days, the participants answered single questions with regards to perceived/estimated EE ( $\mathrm{kcal}$ ) (E and NE sessions) and perceived EI ( $\mathrm{kcal})$ from the food they consumed (post $\mathrm{E}$ and post NE lunch meals) (Appendix C). Specifically they were asked two questions: "How many calories do you think you just expended during the 60 minutes of treadmill walking/rest?"; "How many calories do you think you just consumed with the lunch meal?".

\section{Assessment of Hunger and Desire to Eat}

Visual Analogue Scales (VAS) were used on the E and NE days (pre and post) to rate perceived hunger, fullness, desire to eat, amount deserved to eat, and meal/snack intake 
satisfaction. The scales consisted of a ten-centimeter horizontal line in which the extreme left of the scale represented "not at all" and the extreme right, "extremely" (Appendix D). These VAS were derived from a study conducted by Canty (29).

\section{Assessment of the Concept of Food as a Reward}

The concept of food as a reward was measured using a 5-point Likert scale using the following identities: not at all/none, a little/a little bit, somewhat/a moderate amount, quite a bit, a lot (Appendix E). This scale was completed after the exercise bout on the $\mathrm{E}$ day and after the rest period on the NE day. Specifically the participants were asked: "Right now, how much do you feel you deserve to eat?"; "Right now, do you feel you deserve to eat a treat (a specific food, snack or beverage)?"; "How much of that treat do you feel you deserve to eat right now?".

\section{The Nutrition Attitude Survey}

At the beginning of the NE day, each participant was asked to complete the Nutrition Attitude Survey (NAS) (28). Two sub-scales, Dietary Helplessness (defined as the level of doubt in one's ability to modify unhealthy eating habits) and Nutrition Concern (defined as the level of concern about healthy eating habits) were evaluated.

\section{Statistical Analyses}

Statistical analysis was performed using SPSS version 10.0 software (SPSS Inc. Chicago, III.). One-way ANOVA was used to analyze the difference among the three dietary/restraint status groups (D-HR, ND-HR, ND-LR) on the descriptive characteristics 
of the participants and on the cognitive factors (i.e. perceived EI and EE, hunger, desire to eat, food as a reward, sub-scales of NAS etc.)

A mixed model repeated measures ANOVA was used to analyze the effect of dieting/restraint status (D-HR, ND-HR, ND-LR) on EI (mean difference between PE-EI and EI at rest). The ANOVA had a within subject factor of condition, exercise vs. nonexercise day, and a between subject factor of dieting/restraint status (D-HR, ND-HR, ND-LR). For significant effects, post hoc comparisons of means were carried out using Fisher's Least Significant Difference (LSD) test. To test for differences by dieting status (dieting vs. non-dieting) and by level of restraint (high restraint vs. low restraint) separately, two a priori comparisons were performed among the three groups. To test for differences within each group between the estimated EE and EI and the actual EE and EI (E and NE sessions), a one-sample t-test was performed. A probability level of $p<0.05$ was selected as the criterion for statistical significance for all tests.

\section{RESULTS}

\section{Subject Characteristics}

Descriptive characteristics of the participants are shown in Table 1. Thirty-six women, mean age $26 \pm 7$ (range 23-31 years), completed the study. The D-HR group was significantly older $(\mathrm{p}<0.05)$ than the ND-HR and the ND-LR groups $\left(\mathrm{F}_{(2,33)}=5.2, \mathrm{p}=\right.$ 0.01). There was no significant difference among the three groups in BMI (mean BMI 28 $\left.\pm 3 \mathrm{~kg} / \mathrm{m}^{2}\right)$. 
There was a significant difference $(p<0.05)$ in restraint among the three groups, the DHR and the ND-HR groups had significantly higher scores than the ND-LR group $\left(\mathrm{F}_{(2,33)}\right.$ $=26.7, p=0.001)$. There was a significant difference $(p<0.05)$ in disinhibition, the $D$ HR had a significantly higher mean disinhibition score than the ND-HR and the ND-LR groups $\left(\mathrm{F}_{(2,33)}=4.7, \mathrm{p}=0.01\right)$.

\section{Lunch Energy Intake}

Lunch EI ( $\mathrm{kcal}$ ) by dieting/restraint status and condition ( $\mathrm{E}$ vs. NE day) is shown in Table

2. The mean lunch EI (kcal) for the three groups on the E day and the NE day was $686 \pm$ 318 and $606 \pm 307$ (mean \pm S.D.), respectively. Even though the main effect of condition was not significant $\left(\mathrm{F}_{(1,33)}=1.9, \mathrm{p}=0.18\right)$, there was a main effect of dieting/restraint status $\left(F_{(2,33)}=3.8, p=0.03\right)$. Fisher's LSD test indicated the ND-LR ate significantly more $(\mathrm{p}<0.01)$ across the two days $(\mathrm{E}$ and NE) than the D-HR $(784 \pm 67$ vs. $524 \pm 67)$, a difference of $260 \mathrm{kcal}$.

There was a marginally significant interaction $\left(\mathrm{F}_{(2,33)}=3.2, \mathrm{p}=0.056\right)$ of dieting/restraint status and condition (E vs. NE day) on lunch EI. Fisher's LSD test indicated that the mean difference in lunch $\mathrm{EI}$ (mean $\mathrm{kcal} \pm \mathrm{S}$.D.) between the $\mathrm{E}$ and the NE days was significantly higher $(p<0.05)$ for the D-HR and the ND-LR than for the ND-HR. The DHR and the ND-LR ate $165 \pm 284 \mathrm{kcal}$ and $203 \pm 450 \mathrm{kcal}$ more on the $\mathrm{E}$ than on the NE day, respectively; while the ND-HR ate $127 \pm 301 \mathrm{kcal}$ less on the $\mathrm{E}$ than on the NE day. 


\section{Twelve-hour Energy Intake}

Twelve-hour EI ( $\mathrm{kcal}$ ) by dieting/restraint status and condition ( $\mathrm{E}$ vs. NE day) is shown in Table 2. The mean 12-hour EI (kcal) on the E day and NE day was $1454 \pm 414$ and $1293 \pm 542$, (mean \pm S.D.), respectively. There was no main effect of either condition ( $E$ vs. NE day) $\left(\mathrm{F}_{(1,33)}=2.65, \mathrm{p}=0.113\right)$ or dieting/restraint status $\left(\mathrm{F}_{(2,33)}=2.61, \mathrm{p}=0.089\right)$ on 12-hour EI. However, there was a significant interaction $\left(\mathrm{F}_{(2,33)}=4.12, \mathrm{p}=0.025\right)$ of dieting/restraint status and condition (E vs. NE day) on the 12-hour EI. Fisher's LSD test indicated that the mean difference in 12-hour $\mathrm{EI}$ (mean $\mathrm{kcal} \pm \mathrm{SD}$ ) between the $\mathrm{E}$ and the NE day was significantly higher $(p<0.05)$ for the D-HR than for the ND-HR. The D-HR ate $519 \pm 596 \mathrm{kcal}$ more on the $\mathrm{E}$ than on the NE day; while the ND-HR ate $177 \pm 392$ $\mathrm{kcal}$ less on the $\mathrm{E}$ than on the NE day.

In addition, when the dieters (D-HR) were compared to the non-dieters (ND-HR and NDLR), the dieters (D-HR) ate $519 \pm 596 \mathrm{kcal}$ more on the $E$ than on the NE day $(p<0.01)$. The ND-LR ate only $141 \pm 741 \mathrm{kcal}$ more on the E than on the NE day; and the ND-HR ate $177 \pm 596 \mathrm{kcal}$ less on the $\mathrm{E}$ than on the $\mathrm{E}$ day.

\section{Nutrition Attitude Survey Sub-scales}

There were no significant differences among the three groups in the scores for the two sub-scales, Dietary Helplessness and Nutrition Concern, of the Nutrition Attitude Survey (28). The Dietary Helplessness scores for the D-HR, ND-HR and ND-LR groups were 32 
$\pm 9,28 \pm 7$ and $31 \pm 7$, respectively. The NC scores for the D-HR, ND-HR and ND-LR groups were $13 \pm 2,14 \pm 2$ and $13 \pm 1$, respectively.

\section{Food as a Reward, Hunger and Desire to Eat}

There were no significant differences among the three groups in the scores for the questions assessing the concept of food as a reward (Appendix F) nor for the variables (fullness, desire to eat, amount deserved to eat, and meal/snack intake satisfaction) assessed using the VAS (Appendix G), except for hunger. The D-HR reported to be significantly $(p<0.05)$ hungrier at the beginning of the NE session than the ND-HR and the ND-LR $\left(\mathrm{F}_{(2,33)}=3.38, \mathrm{p}=0.046\right)$.

\section{Estimation of EE and EI of lunch on the $E$ and NE day}

Estimations of EE and EI by dieting/restraint status and condition are shown in Table 3 and Table 4, respectively. There were no significant differences among the three groups in their ability to accurately estimate the EE and lunch $\mathrm{EI}$ on the $\mathrm{E}$ and NE days.

However, we did find that the D-HR was the only group that significantly $(p<0.035)$ underestimated (by approximately $20 \%$ ) their EE on the E day while the ND-HR group significantly $(p<0.039)$ overestimated (by approximately $20 \%)$. The ND-LR overestimated by approximately $10 \%$ but this difference was not significant. All three groups significantly $(p<0.01)$ underestimated their EE in the NE day. The D-HR underestimated their EE by approximately $60 \%$, the ND-HR by $40 \%$ and the ND-LR by $50 \%$. 
All three groups significantly $(p<0.05)$ underestimated their lunch EI on the E day. The D-HR underestimated their EI by approximately $30 \%$, the ND-HR by $25 \%$ and the NDLR by $40 \%$. The three groups also underestimated their EI on the NE day, ranging approximately from $10 \%$ to $25 \%$. However, these differences were not significant.

\section{DISCUSSION}

In this study we investigated the impact of dieting status and restraint on EI after a bout of moderate intensity exercise in sedentary overweight women. The results showed that exercise per se did not have an effect on the EI. This is consistent with similar study designs that have shown that in obese/overweight individuals, EI is independent of EE due to exercise (11-14). However, when we looked at groups with different dieting/restraint status, we found that the group with high restraint and high disinhibition that reported currently dieting increased their 12-hour EI following exercise. This was not the case for the non-dieting groups with either low or high restraint. These results reflect, as has been suggested by Hill et al (21), that dieting status and an individual's cognitive approach to eating and dieting are important factors that could affect PE-EI.

Specifically, Hill et al. (21) have proposed that individuals with high restraint may be less responsive to increased energy demands produced by exercise and that their current dieting status could be the most important variable affecting PE-EI. In their model, Hill et al. (21), proposed that during periods of dieting, overweight disinhibited individuals with high levels of dietary restraint may hold constant or decrease their PE-EI. On the other hand, during periods of non-dieting exercise might provide a stimulus for uncontrolled 
eating episodes among these highly restrained individuals and this might result in an overall positive energy balance.

The eating response after exercise that we observed among the ND-LR in our study is in accordance with what has been proposed in the model of Hill et al. (21). The ND-LR did not increase their EI after their participation in the moderate exercise; as they did not eat more on the E day compared to the NE day. According to the model proposed by Hill et al., overweight unrestrained women are less sensitive to overall energy demands and to physiological cues of hunger and satiety (compared to unrestrained leaner women). Therefore, they may be less likely to compensate (in terms of EI) for changes in EE induced by exercise. Unexpectedly, the post-exercise eating response observed in our study among the D-HR and was contradictory to the theory of Hill et al. (21). According to their model, we had predicted that the D-HR would decrease their PE-EI. Instead, we found that the D-HR increased their12-hour EI.

Perhaps the eating responses observed in the ND-HR and the D-HR group can be explained by Lowe's (30) three-dimensional model of dieting-behavior. This model suggests that the eating behavior of highly restrained eaters can be described with three factors: (1) frequency of dieting and overeating, (2) current dieting and (3) weight suppression via dieting. Lowe (30) has suggested that highly restrained eaters with low disinhibition (such as our ND-HR sample) are probably individuals that have dieted frequently in the past, are currently trying to diet, and are successful at suppressing weight gain. This could mean, as we have observed in our study, that they are better at 
constantly controlling their EI, plus cognitively they might be aware that the EE due to the moderate activity might assist them in attaining negative energy balance.

Lowe (30) has also proposed that individuals with high restraint and high disinhibition (such as our D-HR sample), may represent individuals who have a history of frequent dieting, are currently attempting to diet, and yet they struggle with their attempts to loose weight due to episodic overeating related to a high level of disinhibition. Our sample of high restraint/disinhibited dieters (D-HR) who ate more during the 12-hour period following the E session compared to the NE day, could be an example of an uncontrolled eating episode.

It can be hypothesised that such a counter-regulatory eating response to physical activity could eventually lead to unsuccessful weight loss attempts where dieting and exercise are being employed as the weight reduction methods. Over the long run, it could possibly also lead to significant weight fluctuations. In fact, studies have shown that high disinhibition scores, independent of an exercise component, are significantly related to weight gain and weight cycling, higher BMI, higher EI and patterns of overeating (3134). Additionally, Folgelholm et al. (35) have reported that within a 52-week weight reduction (very low calorie diet)/weight maintenance (walking program) intervention the best predictors of weight maintenance were lower disinhibition score and greater number of daily steps. 
It has been proposed that various "disinhibitors" trigger the loss of self-control and overeating episodes among high restraint/disinhibited individuals $(36,37)$. It has been found that pre-loads of food, ingestion of alcohol and dysphoric emotions (i.e. depression, anxiety) as well as diet-related images and commercials are potential stimulus for "disinhibited" eating behavior and disrupted dieting efforts $(22,38)$. It has also been suggested that increases in exercise might be one such "disinhibitor" (21). Furthermore, Bellisle (36) has stated that after exercise, high restraint/disinhibited eaters may become more vulnerable to external and internal influences that orient food intake in the wrong direction. It is possible that in our study the exercise session specifically became a precipitating factor for disinhibited eating behavior among the D-HR. In other words, perhaps after the exercise session the D-HR felt they could allow themselves a little more flexibility. Thus, their food choices became more permissive leading to an increased PEEI compared to the NE day. Probably the NE day represented a normal dieting day for the sedentary, overweight D-HR group, during which time their efforts to diet and lose weight were not disrupted by any unusual external factors/cues (i.e. exercise).

Contrarily, exercise did not appear to induce either energy compensation or dietary disinhibition and among the ND-HR group. In a similar study conducted by Lluch et al. (24), an exercise bout did not induce dietary disinhibition among a sample of twelve restrained females, ten of them not currently dieting. However, it is important to note that contrary to our study, the women that were used in Lluch's et al. (24) study were normal weight, regular exercisers that were exposed to high intensity exercise (cycling at $70 \%$ $\mathrm{VO}^{2} \max$ for $50 \mathrm{~min}$ ). Several studies have shown that higher intensity exercise can have 
a stronger suppressive impact on EI and/or hunger than lower intensity levels among lean males and females $(13,17,39,40)$. The impact of different exercise intensities on EI has not been observed among obese women $(11,13)$.

It has also been suggested that cognitive factors (i.e. perceptions related to exercise $\mathrm{EE}$, exercise exertion, induced hunger and desire to eat, etc.) are likely to influence PE-EI $(11-13,17,39,41,42)$. In some people, it may even be that such factors outweigh any physiological or metabolic responses (such as suppression or increase of appetite and/or hunger) induced by exercise. In the present study, our participants showed an inability to cognitively assess caloric expenditure and caloric intake accurately. The dieters tended to underestimate the EE of the exercise bout (although significant, it was only $20 \%$ below the actual value), while the non-dieters with high restraint overestimated it (by approximately $20 \%$ ). Others have reported inaccuracies (overestimation of $51 \%$ ) in the estimation of the total time spent in physical activity and thus, in the indirect estimation of total EE for exercise and physical activity (43). It is still unclear whether the cognitive inability to accurately estimate EE has an impact on short or long-term energy balance. Most importantly, all three groups underestimated their EI with the E lunch meal (as much as $40 \%$ ). It has been previously reported that obese and non-obese subjects are likely to underestimate self-reported EI $(43,44)$. This suggests that inaccuracies in cognitive estimation of EE and EI might play a role in eating behavior and weight management. Therefore, weight counseling should include accurate information on both the energy content of foods and the EE related to physical activity and exercise. 
Our experimental design had some limitations. First of all, the fact that our study was carried out in free-living conditions (i.e. university cafeteria) might have triggered food choices based on the immediate environment, food availability and/or time of day. These factors have been reported to influence EI in general $(15,21,36)$. On the other hand, our study was unique in that it was conducted in a natural setting that was familiar to the participants in contrast to a laboratory $(11-13,23,24)$. It has been suggested that laboratory conditions can provide precise measurements, however, such an artificial situation might not reflect true daily eating behavior as it provides limited and imposed food choices $(16,36)$.

Another conceivable limitation of our study was the use of self-reported food diary to assess EI after the experimental condition (12-hour EI). The diary could have provided an accurate (i.e. actual EI) but not a valid (i.e. normal EI) measurement of EI since the participants might have felt evaluated and thus, altered their typical eating habits (45). Finally, the standard breakfast may not have been part of the participants' daily eating routine and it may have had an impact on the lunch and/or 12-hour EI.

\section{CONCLUSION AND APPLICATION}

The results of this study showed that among overweight sedentary women, dieting/restraint status was a decisive component of the eating response after 1 hour of moderate intensity exercise. In summary, individuals who identified themselves as dieting and who had high restraint increased their EI after exercising. This may have been due to some level of disinhibition triggered by the exercise experience. The results of this 
study suggest that dieting status, level of disinhibition as well as cognitive factors should be considered by health care professionals when including exercise as a part of prescription for weight management. 


\section{Table 1}

Descriptive characteristics of the participants ${ }^{2}$

$\begin{array}{lll}\text { D-HR } & \text { ND-HR } & \text { ND-LR } \\ (\mathrm{n}=12) & (\mathrm{n}=12) & (\mathrm{n}=12)\end{array}$
Age (years)
$31 \pm 8^{b}$
$23 \pm 3^{c}$
$25 \pm 8^{c}$
Weight (lbs.)
$157 \pm 22$
$152 \pm 18$
$172 \pm 26$
Height (inches)
$62 \pm 5$
$64 \pm 2$
$64 \pm 2$
$\operatorname{BMI}\left(\mathrm{kg} / \mathrm{m}^{2}\right)$
$28 \pm 3$
$27 \pm 2$
$30 \pm 3$
Restraint
$14 \pm 4^{b}$
$14 \pm 3^{b}$
$5 \pm 3^{\circ}$
Disinhibition
$10 \pm 3^{b}$
$6 \pm 3^{c}$
$6 \pm 3^{c}$
Hunger
$7 \pm 3$
$5 \pm 2$
$5 \pm 3$

${ }^{a}$ Mean \pm SD

${ }^{b, c}{ }^{c}$ Means in rows with different superscripts are significantly different according to Fisher's LSD ( $p<$ $0.05)$. 
Table 2

Energy intake (kcal) by dieting/restraint status and condition, exercise (E) vs. non-exercise (NE) day ${ }^{a}$

Dieting/

restraint status

$$
\text { Lunch }
$$

(kcal) 12-hours

(kcal)

$\begin{array}{ccccc} & \text { E } & \text { NE } & \text { E } & \text { NE } \\ \text { D-HR } & 607 \pm 256 & 442 \pm 187 & 1496 \pm 445^{\mathrm{b}} & 978 \pm 556^{\mathrm{c}} \\ \text { ND-HR } & 565 \pm 249 & 693 \pm 326 & 1246 \pm 224 & 1422 \pm 380 \\ \text { ND-LR } & 886 \pm 357 & 683 \pm 339 & 1621 \pm 467 & 1480 \pm 564\end{array}$

${ }^{\mathrm{a}} \mathrm{Mean} \pm \mathrm{SD}$

${ }^{b, c}$ Means in rows with different superscripts are significantly different $(p<0.01)$. 
Table 3

Participant estimation in calories of post-exercise energy expenditure (PE-EE) compared to actual PE-EE

Dieting/

restraint status

E Day

NE Day

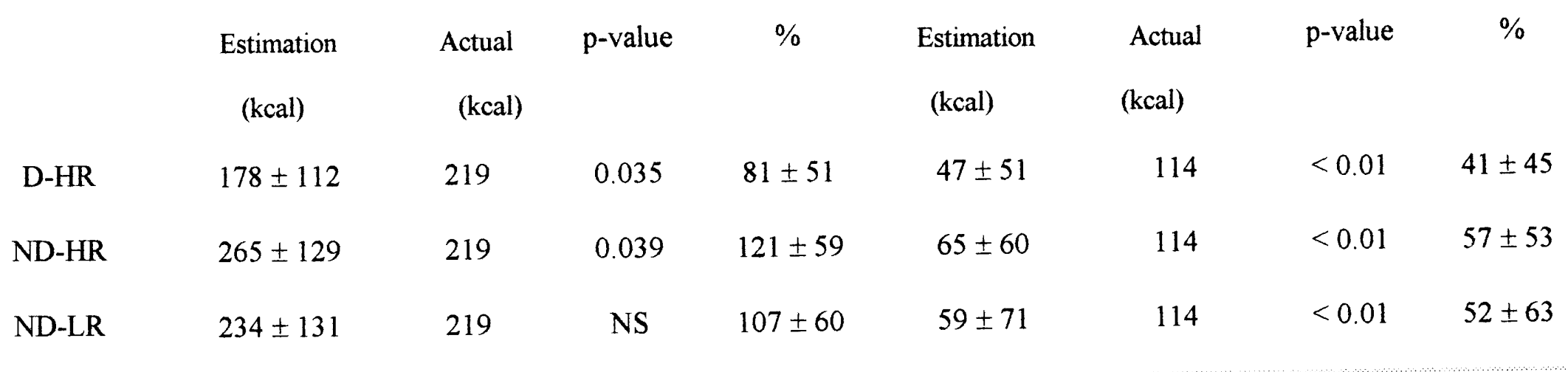

${ }^{a}$ Mean \pm SD 


\section{Table 4}

\section{Participant estimation in calories}

of post-exercise energy intake (PE-EI) compared to actual PE-EI ${ }^{\text {a }}$

Dieting/

restraint status

$$
\text { E Day }
$$

NE Day

$\begin{array}{lcccccccc} & \text { Estimation } & \text { Actual } & \text { p-value } & \% & \text { Estimation } & \text { Actual } & \text { p-value } & \% \\ & (\mathrm{kcal}) & (\mathrm{kcal}) & & & (\mathrm{kcal}) & (\mathrm{kcal}) & & \\ & 432 \pm 229 & 607 \pm 256 & 0.017 & 72 \pm 30 & 359 \pm 117 & 442 \pm 187 & 0.68 & 87 \pm 28 \\ \text { D-HR } & 370 \pm 149 & 565 \pm 249 & 0.032 & 75 \pm 37 & 439 \pm 148 & 693 \pm 326 & 0.070 & 76 \pm 38 \\ \text { ND-HR } & 507 \pm 303 & 886 \pm 357 & <0.01 & 59 \pm 33 & 437 \pm 285 & 683 \pm 339 & 0.068 & 84 \pm 78 \\ \text { ND-LR } & & & & & & & \end{array}$

${ }^{a}$ Mean \pm SD 


\section{REFERENCES}

1. Tremblay A, Doucet E, Imbeault P. Physical activity and weight maintenance. Int J Obes Relat Metab Disord. 1999;23(supppl 3):S50-45.

2. Westerterp KR. Obesity and physical activity. Int J Obes Relat Metab Disord. 1999;23(suppl 1):S59-64.

3. Tremblay A, Doucet E. Influence of intense physical activity on energy balance and body fatness. Proc Nutr Soc. 1999;58:99-105.

4. American College of Sports Medicine. Guidelines for Exercise Testing and Prescription. Baltimore: Lippincott Williams \& Wilkin, 2000, pp. 68, 143-151.

5. Mole PA. Impact of energy intake and exercise on resting metabolic rate. Sports Med. 1990; 10:72-87.

6. Poehlman ET. A review: exercise and its influence on resting energy metabolism in man. Med Sci Sports Exerc. 1989;21: 515-25.

7. Van Zant RS. Influence of diet and exercise on energy expenditure: a review. Int J Sport Nutr. 1992;2:1-19.

8. Flatt JP. Dietary fat, carbohydrate balance, and weight maintenance: effects of exercise. Am J Clin Nutr. 1987;45:296-306.

9. Roberts SB, Young VR, Fuss $\mathbf{P}$, et al. Energy expenditure and subsequent nutrient intakes in overfed young men. Am J Physiol. 1990;259:R461-9.

10. Bryner RW, Toffle RC, Ullrich IH, Yeater RA. The effects of exercise intensity on body composition, weight loss, and dietary composition in women. $J \mathrm{Am}$ Coll Nutr. 1997;16:68-73.

11. Woo R, Garrow JS, Pi-Sunyer FX. Effect of exercise on spontaneous calorie intake in obesity. Am J Clin Nutr. 1982;36:470-7. 
12. Woo R, Garrow JS, Pi-Sunyer FX. Voluntary food intake during prolonged exercise in obese women. Am J Clin Nutr. 1982;36:478-84.

13. Kissilef HR, Pi-Sunyer FX, Segal K. Acute effects of exercise on food intake in obese and non-obese women. Am J Clin Nutr. 1990;52:240-5.

14. Kleim NL, Canty DJ, Barbieri TF, Wu MM. Effect of exercise and dietary restraint on energy intake of reduced obese women. Appetite. 1996;26:55-70.

15. Blundell JE, King NA. Physical activity and regulation of food intake: current evidence. Med Sci Sports Exerc. 1999;31(suppl):S573-83.

16. King NA, Tremblay A, Blundell JE. Effects of exercise on appetite control: implications for energy balance. Med Sci Sports Exerc. 1997;29:1076-89.

17. Woo R, Pi-Sunyer FX. Effect of increased physical activity on voluntary intake in lean women. Metabolism. 1982;34:836-41.

18. Durrant ML, Royston JP, Wloch RT. Effects of exercise on energy intake and eating patterns in lean and obese humans. Physiol Behav. 1982;29:449-54.

19. Verger P, Lanteaume MT, Louis-Sylvestre J. Free food choices after acute exercise in men. Appetite. 1994;22:159-64.

20. Verger P, Lanteaume MT, Louis-Sylvestre J. Human intake and choices of foods at intervals after exercise. Appetite. 1992;18:93-9.

21. Hill JO, Melby C, Johnson SL, Peters JC. Physical activity and energy requirements. Am J Clin Nutr. 1995;62(suppl):1059S-66.

22. Ruderman, A J. Dietary Restraint: A Theoretical and Empirical Review. Psychol Bull. 1989;99:247-62. 
23. King NA, Snell L, Smithe RD, Blundell JE. Effects of short-term exercise on appetite responses in unrestrained females. Eur J Clin Nutr. 1996;50:663-7.

24. Lluch A, King NA, Blundell JE. Exercise in dietary restrained women: No effect on energy intake but change in hedonic ratings. Eur J Clin Nutr. 1998;52:300-7.

25. Stunkard AJ, Messick S. The three-factor eating questionnaire to measure dietary restraint, disinhibition and hunger. J Psychosom Res. 1985;29:71-83.

26. Powers SK, Howley ET. Exercise physiology: Theory and applications to fitness and performance. Massachussetts: McGraw Hill, $3^{\text {rd }}$ edition, pp. 481-4.

27. Abbott M. Portion Photos of Popular Foods. Published by the American Dietetic Association.

28. Hollis JF, Carmody TP, Connor SL, Fey SG, Matarazzo JD. The Nutrition Attitude Survey: Association with dietary habits, psychological and physical wellbeing, and coronary risk factors. Health Psychol. 1986;5:359-74.

29. Canty, DJ. The effects of exercise, diet and eating restraint factors on appetite, emotions, and dietary intake in reduced-obese women. Dissert Abstr Int.: Section B: The Sciences \& Engeneering, Vol 58 (10-B), Apr 1998, 5333.

30. Lowe MR. The effect of dieting on eating behavior: a three-factor model. Psychol Bull. 1993;114:100-21.

31. Carmody TP, Brunner RL, St-Jeor ST. Dietary helplessness and disinhibition in weight cyclers and weight maintainers. Int J Eat Disord. 1995;18:247-56.

32. McGuire MT, Wing RR, Klem ML, Lang W, Hill JO. What predicts weight regain in a group of successful weight losers? J Consult Clin Psychol. 1999;67:177-85.

33. Lawson OJ, Williamson DA, Champagne CM, et al. The association of body weight, dietary intake and energy expenditure with dietary restraint and disinhibition. Obes Res. 1995;3:153-61. 
34. Westenhoefer J, Stunkard AJ, Pudel V. Validation of the flexible and rigid control dimensions of dietary restraint. Int J Eat Disord. 1999;1:53-64.

35. Folgelholm M, Kukkonen-Harjula K, Oja P. Eating Control and physical activity as determinants of short-term weight maintenance after a very-low-calorie diet among obese women. Int J Obes Relat Metab Disord. 1999;23:203-10.

36. Bellisle F. Food choice, appetite and physical activity. Public Health Nutr. 1999;2(3a): 357-61.

37. Herman CP, Polivy J. In: Eating and its Disorders. A boundary model for the regulation of eating. New York: Raven Press, 1984, pp.141-56.

38. Strauss J, Doyle AE, Kreipe RE. The paradoxical effect of diet commercials on reinhibition of dietary restraint. J Abnorm Psychol. 1994;103:441-4.

39. Thompson DA, Wolfe LA, Eikelboom R. Acute effects of exercise intensity on appetite in young men. Med Sci Sports Exerc. 1988;20:222-7.

40. King NA, Burley JE, Blundell JE. Exercise-induced suppression of appetite: effects on food intake and implications for energy balance. Eur J Clin Nutr. 1994;48:715-24.

41. King NA. What processes are involved in the appetite responses to moderate increase in exercise-induced energy expenditure? Proc Nutr Soc. 1999;58:107-13.

42. Hubert P, King NA, Blundell JE. Uncoupling the effects of energy expenditure and energy intake: appetite response to short-term energy deficit induced by meal omission and physical activity. Appetite. 1998;31:9-19.

43. Lichtman SW, Pisarka K, Berman ER, et al. Discrepancy between self-reported and actual caloric intake and exercise in obese subjects. $N$ Engl J Med. 1992;327:1893-8.

44. Bandini LG, Schoeller DA, Cyr HN, Dietz WH. Validity of reported energy intake in obese and non-obese adolescents. Amer J Clin Nutr. 1990;52:421-5. 
45. Hill JA, Rogers PJ, Blundell JE. Techniques for the experimental measurement of human eating behavior and food intake: a practical guide. Int J Obes. 1995;19:36175. 
(Page 1 of 2)

\section{Debriefing Questionnaire}

\section{Please circle your answer for each question}

1. Were your food choices at lunch different on the exercise day compared to the non-exercise day?
A. No
B. Yes
C. Don't remember
If yes, please explain why you think you ate differently on the exercise day compared to the non-exercise day?

2. On the exercise day, do you think you ate:
A. More than the non-exercise day
B. Less than the non-exercise day
C. The same amount as the non-exercise day

3. Were you still hungry after lunch on the day that you exercised?
A. No
B. Yes
C. Don't remember
If yes (you were still hungry after lunch), please explain why didn't you eat more?

4. Were you still hungry after lunch on the day that you did not exercise?
A. No
B. Yes
C. Don't remember
If yes (you were still hungry after lunch), please explain why didn't you eat more?

5. For lunch do you usually:
A. Buy your lunch at the cafeteria
B. Bring your lunch from home
C. Go to a restaurant
D. Skip lunch
E. Other 
6. For lunch do you usually:
A. Eat the same thing everyday
B. Eat something similar everyday (i.e. a sandwich)
C. Eat something different everyday
D. Skip lunch
E. Other

7. How do you think that exercise affects the amount that you eat?
A. Increases the amount
B. Decreases the amount
C. No effect

8. Do you think that regular exercise is important?
A. No
B. Yes
If "yes", why is it that you do not exercise on a regular basis?
A. No time
B. Don't enjoy it
C. Don't know what type of exercise to do
D. Health problems
E. Other

9. Would you like to lose weight?
A. No
B. Yes

10. Do you think that it is important to lose weight?
A. No
B. Yes

If "yes", please explain why?

11. Do you think it is bad for your health to be overweight?
A. No
B. Yes 


\section{Appendix: B}

(Page 1 of 1)

\section{Instructions for a Standard Breakfast}

Breakfast on both days should be identical or very similar You do not have to eat all of this but you must eat breakfast. It should consist of the food items listed below. If a food that you normally eat for breakfast is not on this list please discuss this with the study coordinator before you begin the study.

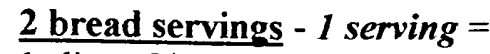

1 slice of French bread

1 small piece Italian/Cuban bread

$1 / 2$ bagel, 1 small muffin

$1 / 2$ English muffin

1 small bread roll

1 tortilla 6" across

$1 / 2 \mathrm{C}$ oatmeal

$1 / 2 C$ ready to eat unsweetened cereal

3 graham crackers

6 saltine-type crackers

2-4 whole wheat crackers

1 biscuit

1 cornbread 2" cube

2 pancakes 4" across

1 waffle $4 \frac{1}{2}$ square

$1 / 4 \mathrm{C}$ granola

1 milk serving (optional) -1 serving $=$

1C milk

$1 / 2 \mathrm{C}$ evaporated milk

$1 \mathrm{C}$ buttermilk

3/4-1C yogurt

1 fat serving -1 serving $=$

1 tbs. cream cheese

1 tbs. cream cheese

2 tbs. sour cream

$1 \mathrm{tsp}$. butter or margarine

$1 / 8$ medium avocado

If you choose peanut butter as your meat serving, please omit the fat serving

\section{2 sugar servings -1 serving $=$}

3 tsp. sugar (can be used in coffee or tea) or 2 tsp. jam/jelly or 1-2 tbs. syrup, honey

Drinks: You may drink coffee, tea, water, milk, juice, etc. If you drink milk (even in you include it in your coffee or tea) or juice you have to count them as milk or fruit serving.
1 fruit serving -1 serving $=$

1 small apple, orange, mandarin, pear

$3 / 4 \mathrm{C}$ berries

$1 / 2$ small mango

$1 / 2$ banana

$1 / 2$ C fruit juice

$1 / 2 \mathrm{C}$ apple sauce

$1 \mathrm{C}$ cantaloupe, honeydew melon cubes

$1 \mathrm{C}$ papaya cubes

$3 / 4 \mathrm{C}$ pineapple cubes

$11 / 4 \mathrm{C}$ watermelon cubes

$1 / 2 \mathrm{C}$ canned fruit cocktail

$1 \frac{1}{4} \mathrm{C}$ whole strawberries

2 tbs. raisins

1 meat/meat substitute serving

loz cheese

1 egg

2 egg whites

1/4 C egg substitute

$2 \mathrm{~T}$ peanut butter

$1 / 4 \mathrm{C}$ cottage cheese

$1 \mathrm{oz}$ ham

loz bacon 


\section{Appendix: $\mathbf{C}$}

(Page 1 of 2)

\section{Perceived Energy Expenditure and Energy Intake}

- How many calories do you think you just expended during these 60 minutes of treadmill walking?

- How many calories do you think you just expended during these 60 minutes of rest?

- How many calories do you think you just consumed with this lunch meal? (given after the lunch meal on both the $\mathrm{E}$ and $\mathrm{NE}$ day) 


\section{Appendix: D}

(Page 1 of 2)

\section{Visual Analogue Scales}

Please read each of the following questions and answer them carefully. Answer the questions by making a small mark with a pen on the answer line below the question.

1) How alert do you feel right now?

Not at all I

I Extremely

alert alert

2) How hungry do you feel right now?

Not at all $\mathrm{I}$

hungry

I Extremely

hungry

3) How tired do you feel right now?

Not at all I

I Extremely

tired tired

4) How full does your stomach feel right now?

Not at all I

I Extremely

full

full

5) How relaxed do you feel right now?

Not at all I

I Extremely

relaxed

relaxed

6) How thirsty do you feel right now?

Not at all $\mathrm{I}$

I Extremely

thirsty

thirsty

7) How is your mood right now?

My worst I

I My best

mood mood 
8) How strong is your desire to eat right now?

Not at all I

I Extremely

strong strong

9) How tense do you feel right now?

Not at all I

I Extremely

tense

tense

10) How much food do you think you deserve to eat right now?

Nothing I

I An extremely

at all

large amount

11) How sleepy do you feel right now?

Not at all $\mathrm{I}$

I Extremely

sleepy

sleepy

12) How nauseated do you feel right now?

Not at all I

I Extremely

nauseated

nauseated

13) If right now you could eat a meal or a snack, how satisfying would you find it?

Not at all I

I Extremely satisfying satisfying

14) If right now you just finished exercising, how strenuous did you find it?

Not at all I stremuous
I Extremely strenuous

15) How anxious do you feel right now?

Not at all I

anxious
I Extremely

anxious 
Appendix: E

(Page 1 of 1$)$

“Food as a Reward" Questionnaire

Please mark your answer with an $\mathrm{X}$.

1. Right now, how much do you feel you deserve to eat? NOT AT ALL

A LITTLE

SOMEWHAT

QUITE A BIT

A LOT

2. Right now, do you feel you deserve to eat a treat (a specific food, snack or beverage)?

NOT AT ALL

A LITTLE

SOMEWHAT

QUITE A BIT

A LOT

If you do feel like having a treat, what would it be?

3. How much of that treat do you feel you deserve to eat right now?

NONE

A LITTLE BIT

A MODERATE AMOUNT

QUITE A BIT

A LOT 


\begin{tabular}{|c|c|c|c|c|c|c|}
\hline & \multicolumn{2}{|c|}{$D-H R(n=12)$} & \multicolumn{2}{|c|}{ ND-HR $(n=12)$} & \multicolumn{2}{|c|}{ ND-LR $(n=12)$} \\
\hline & E Day & NE day & E Day & NE day & E Day & NE day \\
\hline $\begin{array}{l}\text { How much of that } \\
\text { treat } \\
\text { None }\end{array}$ & $3(25.0 \%)$ & $5(41.7 \%)$ & $2(16.7 \%)$ & $3(25.0 \%)$ & $5(41.7 \%)$ & $6(50.0 \%)$ \\
\hline A little bit & $1(8.3 \%)$ & $1(8.3 \%)$ & $1(8.3 \%)$ & $3(25.0 \%)$ & $1(8.3 \%)$ & $4(33.3 \%)$ \\
\hline Moderate amount & $7(58.3 \%)$ & $5(41.7 \%)$ & $5(41.7 \%)$ & $4(33.3 \%)$ & $3(25.0 \%)$ & $2(16.7 \%)$ \\
\hline Quite a bit & $1(8.3 \%)$ & $1(8.3 \%)$ & $2(16.7 \%)$ & $1(8.3 \%)$ & $2(16.7 \%)$ & $0(0 \%)$ \\
\hline A lot & $0(0 \%)$ & $0(0 \%)$ & $1(8.3 \%)$ & $1(8.3 \%)$ & $1(8.3 \%)$ & $0(0 \%)$ \\
\hline
\end{tabular}

${ }^{3}$ Frequencies and percentages 


\section{Appendix: G}

\section{Table 5}

(Page 1 of 1 )

Reported variables on the VAS by dieting/restraint status and treatment, exercise (E) vs. non-exercise (NE) day ${ }^{\text {a }}$

\begin{tabular}{lccccccc} 
& \multicolumn{2}{c}{ D-HR $(\mathrm{n}=12)$} & \multicolumn{2}{c}{ ND-HR $(\mathrm{n}=12)$} & \multicolumn{2}{c}{ ND-LR $(\mathrm{n}=12)$} \\
& E Day & NE Day & E Day & NE Day & E Day & NE Day \\
$\begin{array}{c}\text { Hunger } \\
\text { pre-session }\end{array}$ & $3.5 \pm 3.3$ & $4.3 \pm 2.3^{\mathrm{b}}$ & $2.5 \pm 3.3$ & $1.8 \pm 2.4^{\mathrm{c}}$ & $2.3 \pm 2.7$ & $2.2 \pm 2.9^{\mathrm{c}}$ \\
$\begin{array}{c}\text { Hunger } \\
\text { post-session }\end{array}$ & $4.7 \pm 2.3$ & $5.7 \pm 2.4$ & $4.8 \pm 3.6$ & $4.0 \pm 3.0$ & $4.8 \pm 3.1$ & $4.5 \pm 3.7$ \\
$\begin{array}{c}\text { Pre session } \\
\text { post session }\end{array}$ & $-1.2 \pm 3.1$ & $-1.3 \pm 2.8$ & $-2.3 \pm 3.2$ & $-2.2 \pm 2.7$ & $-2.5 \pm 2.4$ & $-2.3 \pm 3.7$ \\
$\begin{array}{c}\text { Fullness } \\
\text { pre-session }\end{array}$ & $3.3 \pm 2.8$ & $4.0 \pm 2.4$ & $4.9 \pm 3.1$ & $5.6 \pm 2.9$ & $5.2 \pm 3.1$ & $4.7 \pm 3.1$ \\
$\begin{array}{c}\text { Fullness } \\
\text { post-session }\end{array}$ & $3.0 \pm 1.7$ & $2.6 \pm 1.8$ & $3.3 \pm 3.3$ & $3.9 \pm 2.3$ & $2.2 \pm 2.7$ & $4.3 \pm 3.5$ \\
$\begin{array}{c}\text { Pre session } \\
\text { post session }\end{array}$ & $0.3 \pm 2.4$ & $1.3 \pm 1.3$ & $1.5 \pm 3.9$ & $1.7 \pm 2.8$ & $2.9 \pm 2.8$ & $0.4 \pm 1.7$ \\
$\begin{array}{c}\text { Desire to eat } \\
\text { pre-session }\end{array}$ & $3.6 \pm 3.0$ & $3.5 \pm 2.5$ & $2.1 \pm 2.9$ & $2.4 \pm 2.7$ & $1.8 \pm 2.4$ & $2.4 \pm 3.2$ \\
$\begin{array}{c}\text { Desire to eat } \\
\text { post-session }\end{array}$ & $4.8 \pm 1.6$ & $5.7 \pm 2.4$ & $5.3 \pm 3.3$ & $4.2 \pm 3.1$ & $4.9 \pm 2.7$ & $4.9 \pm 3.7$ \\
$\begin{array}{c}\text { Pre session- } \\
\text { post session }\end{array}$ & $-1.2 \pm 3.2$ & $-2.2 \pm 2.1$ & $-3.2 \pm 3.3$ & $-1.8 \pm 2.6$ & $-3.1 \pm 2.5$ & $-2.5 \pm 2.8$ \\
$\begin{array}{c}\text { mount deserved pre- } \\
\text { session }\end{array}$ & $2.3 \pm 2.7$ & $3.0 \pm 1.5$ & $1.8 \pm 2.0$ & $2.0 \pm 2.6$ & $2.1 \pm 2.2$ & $2.4 \pm 2.2$
\end{tabular}




\begin{tabular}{|c|c|c|c|c|c|c|}
\hline & \multicolumn{2}{|c|}{ D-HR $(n=12)$} & \multicolumn{2}{|c|}{ ND-HR $(n=12)$} & \multicolumn{2}{|c|}{ ND-LR $(n=12)$} \\
\hline & E Day & NE Day & E Day & NE Day & E Day & NE Day \\
\hline $\begin{array}{l}\text { Amount deserved post- } \\
\text { session }\end{array}$ & $3.7 \pm 2.0$ & $4.8 \pm 1.9$ & $4.2 \pm 2.3$ & $3.6 \pm 2.6$ & $3.9 \pm 2.2$ & $4.3 \pm 2.5$ \\
\hline $\begin{array}{l}\text { Pre session- } \\
\text { post session }\end{array}$ & $-1.4 \pm 3.0$ & $-1.8 \pm 1.7$ & $-2.4 \pm 2.1$ & $-1.5 \pm 2.5$ & $-1.7 \pm 2.3$ & $-1.9 \pm 2.2$ \\
\hline $\begin{array}{l}\text { Food intake satisfaction } \\
\text { pre-session }\end{array}$ & $4.0 \pm 3.4$ & $5.6 \pm 3.1$ & $2.4 \pm 3.2$ & $2.7 \pm 3.1$ & $3.6 \pm 3.3$ & $4.4 \pm 3.2$ \\
\hline $\begin{array}{l}\text { Food intake satisfaction } \\
\text { post -session }\end{array}$ & $6.1 \pm 2.4$ & $7.1 \pm 2.2$ & $5.6 \pm 3.8$ & $5.6 \pm 2.5$ & $4.8 \pm 3.1$ & $5.6 \pm 3.0$ \\
\hline $\begin{array}{l}\text { Pre session- } \\
\text { post session }\end{array}$ & $-2.1 \pm 2.9$ & $-1.6 \pm 2.2$ & $-3.2 \pm 3.5$ & $-2.9 \pm 2.6$ & $-1.2 \pm 3.2$ & $-1.3 \pm 2.3$ \\
\hline
\end{tabular}

